\title{
Widening Participation in Technology Design: \\ A review of the involvement of children with special educational needs and disabilities
}

Laura Benton (corresponding author)

London Knowledge Lab, UCL Institute of Education

23-29 Emerald Street, London, WC1N 3QS

l.benton@ioe.ac.uk

\section{Hilary Johnson}

Dept. of Computer Science, University of Bath

Claverton Down, Bath, BA2 7AY

h.johnson@bath.ac.uk

\begin{abstract}
This article presents a review of the design methods and techniques that have been used to involve children with special educational needs and/or disabilities (SEND) in the technology design process. Situating the work within the established child-computer interaction research sub-field of participatory design, we examine the progress that has been made in relation to the participation of this specific child population. An extensive review of the literature in this area has been undertaken and we describe the different roles, responsibilities and activities that have been undertaken by both the child and adult participants within previous technology design projects. We also highlight the different types of outcome from this previous work involving children with SEND, exploring the impact the children's participation has had on both the resulting technology as well as the impact on the child participants themselves. Finally we conclude this review with a set of reporting recommendations for technology designers and researchers aiming to involve this population in future technology design projects.
\end{abstract}

\section{Keywords}

Technology design process, participatory design, children, special educational needs, disabilities 


\section{Introduction}

The UK government has recently introduced a new Special Educational Needs and Disability (SEND) Code of Practice, which provides guidance for organizations who work with and support this population (DfE \& DfH, 2014). It highlights the requirement for providing children with "the information, advice and support" to enable them to participate in "discussions and decisions about their support", with the use of technology becoming an increasingly important part of this educational support.

A universally accepted definition of what it means 'to participate' is unlikely to exist. However, definitions generally acknowledge that participation encompasses different sets of interests and involves sharing some element of the decision-making affecting one's life or the life of the community in which one lives (Hart, 1992). The key point here is the action of decisionmaking, i.e. being given the opportunity and support to influence rather than simply providing an opinion. Since the establishment of the UN Convention on the Rights of the Child (UNCRC) in 1989 (UNICEF, 2008) a greater importance has been placed on giving children the right to participate fully in family, cultural and social life. However, there is evidence that in establishing this culture of child participation there has been slower progress in the provision of opportunities for children with disabilities (Franklin \& Sloper, 2009). The guidance and regulations laid out in Article 13 of the UNCRC (UNICEF, 2008) state that disabled children should not be assumed to be unable to participate and instead be provided with the appropriate communication aids where necessary.

There are a variety of approaches to participation and one commonly used approach within the field of technology design is participatory design (PD), which enables end users to be actively involved in the decision making process throughout the technology design process. Given the significant impact well-designed technology can have on the lives of children with SEND providing them with an opportunity to participate within the design of this technology is important. The involvement of children in the technology design process is now well established, with many methods and techniques having been developed to facilitate this participation. However, specifically involving children with SEND can be more complex due to the range of additional support needs they may have during the design process and therefore, as with any form of participation in decision-making in society, children with SEND have had more limited opportunities to influence technology design. This is beginning to change, with increased research funding in this area, there are now many more researchers actively seeking to involve children with SEND in the design of new educational and assistive technologies and through this work are developing specific methods and techniques that can be used to support the participation of this population. Although this is a step in the right direction, unfortunately much of this work is constrained to one-off projects and is also spread across a wide range of different research areas. This paper therefore seeks to review the work that has been undertaken in this field, attempting to summarise what has been achieved so far to enable other researchers to build on this, and proposes future directions for the field. Section 5 provides further detail about the scope and the criteria for the inclusion of papers within this review.

Within this paper we examine the different SEND populations that have been previously involved in the technology design process and the roles and activities that the child participants have undertaken as part of their involvement. We consider the various outcomes that have resulted from the participation of children with SEND both in terms of the impact upon the final technology as well as the impact on the participants themselves. We also look at the various roles, responsibilities and activities that adult participants within the technology design process have undertaken and the impact they have had upon the outcome of the process. Lastly we consider the future of this research area and propose a set of recommendations for the reporting of technology design projects involving children with SEND. The primary contributions of this review are therefore:

- An outline of the current state of the art within PD for children with SEND through an extensive review of the literature, (and summarized in Table 1)

- An identification of the major issues in undertaking PD studies involving children with SEND and important factors to take into account when doing so

- A discussion of work still to be done and unresolved issues 
- Recommendations for reporting studies in this area (aimed at both authors and reviewers)

\section{Defining special educational needs and disabilities (SEND)}

The UK Departments for Education and Health (2014) define a child or young person as having SEND if "they have a learning difficulty or disability which calls for special educational provision to be made for him or her". This can mean that they have a significantly greater difficulty in learning than their peers or are hindered from making use of facilities provided in mainstream schools or post-16 institutions. Within this the Departments for Education and Health define four broad areas of need which include:

- Communication and interaction e.g. speech, language and communication needs, or autism spectrum conditions

- Cognition and learning e.g. learning difficulties from moderate to profound and multiple, or specific learning difficulties such as dyslexia, dyscalculia and dyspraxia

- Social, emotional and mental health difficulties e.g. anxiety, depression, eating disorders, attention deficit disorder, attention deficit hyperactivity disorder or attachment disorder

- Sensory and/or physical needs e.g. vision impairments, hearing impairments, multisensory impairments or physical disabilities such as cerebral palsy.

Longer-term health conditions such as cancer may also significantly impact a child's learning and result in them being identified as having SEND.

In designing technology for a SEND population it is important to consider how the concept of 'disability' is positioned within the design process. Two of the most prominent models of disability are the medical model and the social model. The medical model (which can also be referred to as the deficit or individual model) views individuals with disabilities as 'patients', placing the problem with the individual and explaining the concept of disability at an impairment level (Anderberg, 2005; Seelman, 2004). In contrast, the social model, which is more typically adopted by people with disabilities, places the problem with society and views disability more as a diversity in function (Anderberg, 2005; Seelman, 2004). One of the key messages of this model is that "societal structures should be changed to accommodate people with disabilities, not individuals that should be changed to fit into a rigid environment and society" (Anderberg, 2005). Although this model is preferred over the medical model by disability advocates (Seelman, 2004), there are also limitations to this approach. As Mankoff et al. (2010) point out "if disability is truly defined only by society, the experience of impairment is to some extent invalidated", some individuals may experience significant pain and require medical treatment to manage their condition, and placing the onus entirely on society sidelines this important need. Alternative models have been proposed such as the integrative model (Seelman, 2004) and the post-modern model (Mankoff et al., 2010) which attempt to combine the key elements from both models, to provide a more balanced view of disability, although these are less well developed.

Armagno (2012) has highlighted the importance of considering these perspectives within the context of $\mathrm{HCl}$, particularly with respect to assistive technologies, and emphasizes the fact that two meanings are embedded within every developed product or service: firstly it affords what the user can and cannot do and secondly it also represents the designer's view of a "normal" user. Anderberg (2005) suggests that technology and design can be seen as "mediators of disability" and that they have the potential to reinforce existing disabling structures or break these down and create new enabling supports. He goes on to stress that technology and design are "too important to be left only to the technicians and designers", highlighting it as being integral to our culture. Mankoff et al. (2010) propose PD as a potential solution to the issues within assistive technology design to help mitigate concerns over marginalizing atypical users, citing examples of how it has usefully been applied in previous work with disabled adults.

\section{Participatory approaches to technology design}

The field of PD is extremely complex with different researchers using the term in slightly different ways and there being many other design approaches, methods and techniques that 
share similar characteristics to PD, where the user's needs are specifically considered as part of the design process.

The earliest of these is user-centred design (UCD), which shares many of the activities undertaken during PD sessions but has a different underlying philosophy. Unlike the industrial democracy foundations of PD, the philosophy underpinning UCD sessions is the paramount usability of functionality that adheres to user needs. Users can take part in a series of design and prototyping sessions, but are not often explicitly considered as part of the 'design' team. Furthermore, issues of empowerment do not arise as it is assumed that users have domain knowledge and needs which analysts must capture and designers have the expertise to generate solutions that users can respond to. Users are not considered to be in a context of mutual learning within a design team and it is the final product that is of most interest in terms of the user experience, engagement, fun and, traditionally, also productivity.

$P D$ has been prevalent for over 40 years, but more recently has also been referred to as cooperative design or co-design (Carroll, Chin, Rosson, \& Neale, 2000). It is a means of designing technology by actively involving the potential end users as full participants throughout the design process (Rogers, Sharp, \& Preece, 2011). PD originally evolved from the collaborative work between technology designers and labour unions in Scandinavia to enable workers to influence the new computer systems, which were being introduced within their workplaces (Schuler \& Namioka, 1993). However, Sanders and Stappers (2008) state that the philosophy of PD practice today "is focused more on the exploration and identification of presumably positive future opportunities than it is on the identification and amelioration of adverse consequences".

PD is a collaborative process with the designers and end users working together through a process of mutual learning, both contributing their own expertise to the design sessions. The final design should ideally combine the end users' expertise on the technology requirements with the designers' expertise on how to best realise those requirements within a working system; with decisions made democratically and involving all participants (Hussain, 2010). Although the approach was originally developed for use with adult employees in the workplace, it has now been adapted into a number of methods that can be used for a variety of scenarios, including designing technology with children.

A related participatory approach is Informant design, which was specifically developed with the consideration of involving children directly within the technology design process. It seeks to allow children to have more involvement than in traditional UCD, with the aim of addressing the difficulty in establishing equality between children and adults needed within a PD team. This is achieved by reducing the demands placed on the children and removing the requirement for children to be viewed as equal to adults (Scaife \& Rogers, 1999; Scaife, Rogers, Aldrich, \& Davies, 1997). The children are involved at various stages in the technology design process, where it is deemed necessary and appropriate by the adult designers.

Experience-centred design ( $E C D$ ) is a further design approach that shares some values with PD and has been used to involve children in technology design (Durrant et al., 2013), emphasizing the fostering of "empathy and aesthetic engagement between stakeholders". It differs from PD in that it allows the designer to design for a particular community based on this engagement (Durrant et al., 2013) whilst still providing users with a voice within the design process.

Due to the multiple (and sometimes conflicting) definitions and broadness of the term PD an extremely wide range of technology projects have been labeled as following a PD approach. For example Read et al. (2014) define PD as "the involvement of end users as informants in the design of technology" whereas Dearden and Rizvi (2008) highlight the importance of participation "going beyond simply engaging people as informants in design". Within the childcomputer interaction $(\mathrm{CCl})$ community the involvement of child users within a PD process can range from one-off sessions to prolonged involvement over extended periods of time (up to years) (Read et al., 2014). We have therefore reviewed a wide range of papers that have sought to provide opportunities for children with SEND to participate through a number of 
different ways in the design of technology. These may not necessarily have been explicitly defined as PD, but could be seen as a starting point for further participation and opportunities for mutual learning, through the technology design process.

\section{The involvement of children in the technology design process}

The form of participation within a project is often defined in terms of the adult-child interaction within the project and how they share power (Kirby et al., 2003). These forms range from the child having an awareness of the project, but having no power to influence decision-making in any way, through to having, or at least sharing, the power to make the final decision in different aspects of the project. Recently researchers have raised the question of what is considered enough engagement within a project to be defined as participation and how forms of participation can be interpreted differently across domains (Vines et al., 2012).

There are a number of models that attempt to define the different forms of participation. One of the most prominent models depicts these forms as a 'ladder', and suggests in addition to genuine participation there are also three forms of non-participation, where the children are involved in the project but not in a meaningful way. 'The Ladder of Participation' (see Figure 1) was originally proposed by Hart (1992), adapted from Arnstein's 'Eight rungs on the ladder of citizen participation' (Arnstein, 1969), and has since been extremely influential in the field of child participation despite being frequently criticised. The main criticism is that the ladder suggests a hierarchy in which the ultimate goal of a participatory project is to achieve the top rung of 'Child-initiated, shared decisions with adults'. The most appropriate form of participation may vary depending on the nature of the project and the child's individual abilities, characteristics and additional needs, which would be a particularly important consideration in the case of children with SEND.

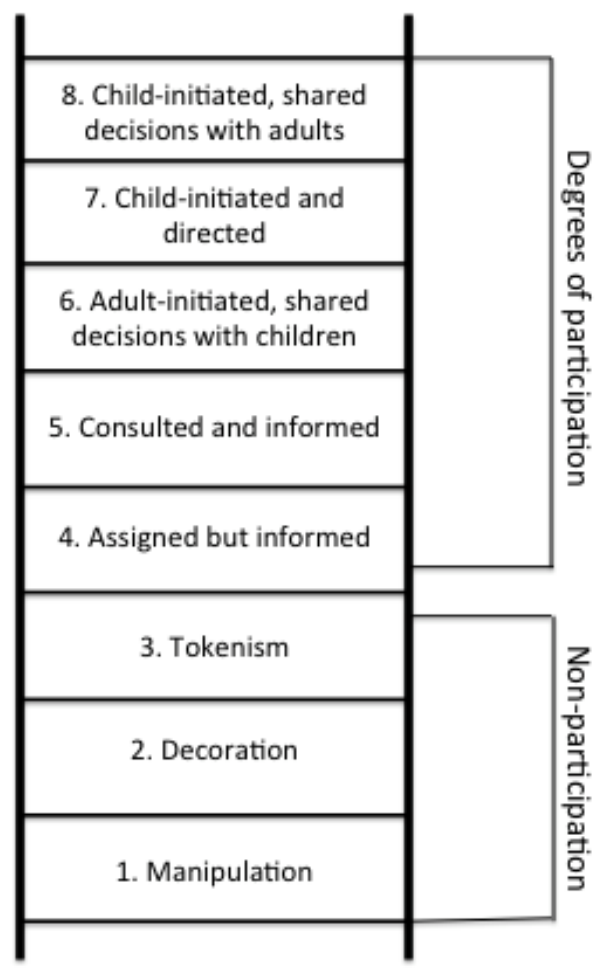

Figure 1 - Ladder of Participation (adapted from (Hart, 1992))

\subsection{Previously defined roles of children in the technology design process}

Within the field of $\mathrm{HCl}$, children participating in the technology design process have similarly had various levels of involvement, which several researchers define as discrete 'roles' to represent these different levels. The most widely recognised of these are the four levels of involvement proposed by Druin (2002), which include the following: 
- User - children contribute to the design process through adult researchers observing them interacting with existing technology and have an indirect impact. From this the researchers can note which aspects the children like as well as any difficulties they may have, which can inform the design of future technologies.

- $\quad T e s t e r$ - the children are observed trialling initial prototypes of the new technology that have been developed and then are directly asked for their feedback by the researchers, which informs future iterations of the technology. This is suitable for children that are able to indicate at the very least whether they like or dislike something. This role is also useful to involve larger numbers of children in the design process, without needing the additional resources required for involving them fully in the initial prototype design.

- Informant - researchers involve the children at various points during the design process when their input is considered of value. This can be through observation of technology interaction, input to prototype designs, or through feedback once the technology has been developed. Design directions can be implied by children's actions rather than specifically expressed directly. This involvement can happen at earlier points in the design process than the tester or user roles and can have a more direct impact on the resulting design, allowing the children to engage in a dialogue with the adult researchers.

- Design Partner - the children act as equal stakeholders throughout the entire design process and are consulted at each stage. This role is similar to the informant role, but crucially the children are considered 'equal partners' and have an equal opportunity to participate at all stages of the design process where it is considered appropriate. They can also elaborate on the ideas of other design team members, both adults and children.

The structure of these levels of involvement could be viewed in a similar way to Hart's ladder of participation and therefore open to the same criticism that the design partner role is seen as the ultimate 'goal'. However, in a recently published paper revisiting these roles Druin and colleagues explicitly state that "This is not to say one [role] is better than the other, only that the roles of informant and design partner are different" (Guha et al., 2012). In addition to these roles, Large et al. (2006) have defined a design method called 'Bonded Design' which involves children at a level of involvement that falls between the informant and design partner roles. The children are involved as partners throughout the process, but Large et al. do not believe that there can be true equality between the children and adult participants in the process.

Furthermore, Read et al. (2002) have identified three modes of participation, which range from Informant Design where the adult designers make the decisions to realize the design, but children are given the opportunity to inform the designers; Balanced Design where there is an equal partnership between the adult and child participants; and Facilitated Design where the adults act as facilitators and the children themselves are expected to initiate the ideas and lead the decision making during the design realization.

\section{The involvement of children with SEND in the technology design process}

\subsection{Literature search}

A review of the relevant literature was conducted in August 2014 and covers literature for the period 2002-2014. It comprises articles that aimed to directly involve children with SEND in the technology design process. To ensure the review covered a wide range of international journal and conference papers both the ACM digital library and Google Scholar databases were searched. The following search terms/keywords were used to identify relevant literature: "participatory design" and "children" and ("special needs" or "disability" or "impairment"). These database searches were additionally supplemented by a prior extensive literature review on PD for children with special educational needs, conducted by the first author over the period 2007-2013 (Benton, 2013) as well as through checking the reference lists of all initially selected papers for further relevant work. Articles were only included if they fulfilled the following criteria:

- Predominantly about children with SEND (rather than adults) 
- Aimed to actively involve children with SEND in the design of technology in some manner

- Provided some form of description about the technology design approach followed (rather than simply stating that a PD approach was followed for instance)

- Did not significantly overlap with another selected paper (this excluded similar papers from the same project)

After applying the above inclusion criteria a total of 46 unique articles were identified, originating from 39 distinct projects, which attempted to involve children with SEND in the technology design process. 


\begin{tabular}{|c|c|c|c|c|c|c|c|c|c|c|c|c|c|c|c|c|c|c|c|c|c|c|c|c|c|c|}
\hline \multirow[b]{2}{*}{ Article } & \multicolumn{14}{|c|}{ SEN and/or Disability of children } & \multirow[b]{2}{*}{$\begin{array}{l}\text { Design } \\
\text { approach }\end{array}$} & \multicolumn{3}{|c|}{$\begin{array}{c}\text { Technology } \\
\text { type }\end{array}$} & \multicolumn{5}{|c|}{$\begin{array}{l}\text { Children's role in design } \\
\text { process }\end{array}$} & \multicolumn{2}{|c|}{$\begin{array}{l}\text { Children's } \\
\text { impact on } \\
\text { tech. }\end{array}$} & \multirow[b]{2}{*}{$\begin{array}{l}\text { Outcomes of } \\
\text { participation for } \\
\text { children }\end{array}$} \\
\hline & $\begin{array}{l}\text { 우 } \\
\text { 玄 } \\
\text { 员 } \\
\text { 安 }\end{array}$ & $\begin{array}{c}\frac{E}{W} \\
\frac{.0}{5} \\
\frac{1}{<}\end{array}$ & 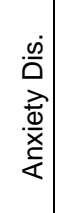 & 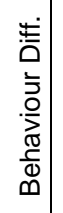 & 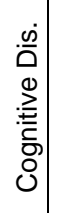 & 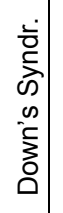 & $\begin{array}{l}\frac{\pi}{x} \\
\frac{0}{\omega} \\
\widehat{\Delta}\end{array}$ & 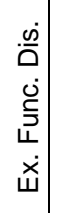 & 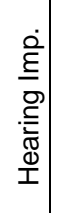 & $\begin{array}{l}\dot{0} \\
\overline{0} \\
0 \\
\overline{0} \\
. \overline{0} \\
\frac{0}{2}\end{array}$ & 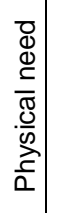 & के & 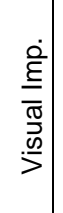 & $\begin{array}{l}\grave{\Phi} \\
\stackrel{ \pm}{ \pm} \\
\end{array}$ & & 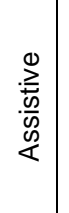 & 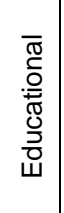 & 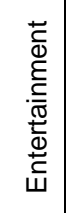 & 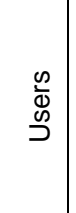 & 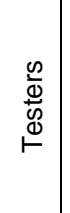 & 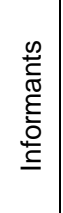 & 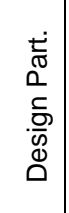 & $\begin{array}{l}\bar{\Phi} \\
\bar{\Phi} \\
\bar{D} \\
\overline{0} \\
\overline{0} \\
\dot{0}\end{array}$ & 芦 & 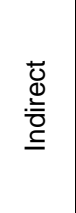 & \\
\hline Al-Wabil et al., 2010 & & & & & & & & & & & & $\mathrm{X}$ & & & $\operatorname{lnD}$ & & $\mathrm{X}$ & & & & $\mathrm{X}$ & & & & & \\
\hline Allsop et al., 2009 & & & & & & & & & & & $\mathrm{X}$ & & & & UCD & $\mathrm{X}$ & & & & & & & & & & $\mathrm{ENJ}^{*}$ \\
\hline Benton et al., 2012 & & $x$ & & & & & & & & & & & & & PD & & $x$ & & & & & $x$ & & & & $\begin{array}{c}\text { ENJ; EM; CO; ENG; } \\
\text { CS; TW; SS* }\end{array}$ \\
\hline Benton \& Johnson, 2013 & & $x$ & & & & & & & & & & & & & PD & & $x$ & & & & & & & & & $\begin{array}{c}\text { ENJ; EM; CO; ENG; } \\
\text { CS; TW; SS* }\end{array}$ \\
\hline Benton et al., 2014 & & $\mathrm{X}$ & & & & & $\mathrm{X}$ & & & & & & & & PD & & $\mathrm{X}$ & & & & & & & & & \\
\hline de Faria Borges et al. 2014 & & & & & & & & & & & $\mathrm{X}$ & & & & PD & $\mathrm{X}$ & & & & & & & $\mathrm{X}$ & & $\mathrm{X}$ & \\
\hline Brederode et al., 2005 & & & & & & & & & & & & & & $\mathrm{X}$ & $\operatorname{lnD}$ & & $\mathrm{X}$ & & & & $\mathrm{X}$ & & & & $\mathrm{X}$ & \\
\hline Culén et al., 2013 & & & & & & & & & & & & & & $\mathrm{X}$ & UCD & & $\mathrm{x}$ & & & & $\mathrm{X}$ & & & & & \\
\hline Durrant et al., 2013 & & & & & & & & & & & & & & $\mathrm{X}$ & ECD & & $\mathrm{X}$ & & & $\mathrm{X}$ & & $\mathrm{X}$ & & $\mathrm{X}$ & $\mathrm{X}$ & $\mathrm{SE}^{\wedge}$ \\
\hline Foss et al., 2013 & $\mathrm{X}$ & $\mathrm{X}$ & $\mathrm{X}$ & & & & & & & & & $\mathrm{X}$ & & & $\mathrm{Cl}$ & & & $\mathrm{X}$ & & & & $\mathrm{X}$ & & & & ENJ; OW* \\
\hline Frauenberger et al., 2010 & & $\mathrm{X}$ & & & & & & & & & & & & & PD & & $\mathrm{X}$ & & & & $\mathrm{X}$ & & & & $\mathrm{X}$ & \\
\hline Frauenberger et al., 2011 & & $\mathrm{X}$ & & & & & & & & & & & & & PD & & $\mathrm{X}$ & & & & $\mathrm{X}$ & & & & $\mathrm{X}$ & \\
\hline Frauenberger et al., 2012 & & $\mathrm{X}$ & & & & & & & & & & & & & PD & & $\mathrm{X}$ & & & & $\mathrm{X}$ & & & & $\mathrm{X}$ & \\
\hline Frauenberger et al., 2013 & & $\mathrm{X}$ & & & & & & & & & & & & & PD & & $\mathrm{X}$ & & & $\mathrm{X}$ & $\mathrm{X}$ & $\mathrm{X}$ & & & $\mathrm{X}$ & EN; SS* \\
\hline Gibson et al., 2002 & & & & $\mathrm{X}$ & & & & & & & & & & & $\mathrm{Cl}$ & $\mathrm{X}$ & & & & & & $\mathrm{X}$ & & $\mathrm{X}$ & & $\mathrm{EM}^{*}$ \\
\hline Grawemeyer et al., 2012 & & $\mathrm{X}$ & & & & & & & & & & & & & $\mathrm{Cl}$ & & $\mathrm{X}$ & & & & & $\mathrm{X}$ & & & & $\mathrm{ENJ}^{*}$ \\
\hline Guha et al., 2008 & $\mathrm{X}$ & & & & & & & $\mathrm{X}$ & & & & & & & $\mathrm{Cl}$ & & & & & & & $\mathrm{X}$ & & & & \\
\hline Henderson et al., 2005 & & & & & & & & & $\mathrm{X}$ & & & & & & ItD & & $\mathrm{X}$ & & & & & & & & & \\
\hline Hernandez et al., 2013 & & & & & & & & & & & $\mathrm{X}$ & & & & PD & & & $\mathrm{X}$ & & & & & & $\mathrm{X}$ & $\mathrm{X}$ & $\mathrm{ENJ}^{*}$ \\
\hline Holone \& Herstad, 2013 & & & & & & & & & & & & & & $\mathrm{X}$ & PD & & $\mathrm{X}$ & & & & & $\mathrm{X}$ & & & & \\
\hline Hornof, 2009 & & & & & & & & & & & $\mathrm{X}$ & & & & $\mathrm{CO}$ & $\mathrm{X}$ & & & & & $\mathrm{X}$ & & & & & $\mathrm{OW}^{*}$ \\
\hline Hourcade et al., 2012 & & $\mathrm{X}$ & & & & & & & & & & & & & & & $\mathrm{X}$ & & & & & & & & & $E N J^{\wedge}$ \\
\hline Hussain, 2010 & & & & & & & & & & & $\mathrm{X}$ & & & & PD & & & & & & $\mathrm{X}$ & & & & & $\mathrm{FoC}^{*}$ \\
\hline Iversen et al., 2007 & & & & & & & & & $\mathrm{X}$ & & & & & & PD & & $\mathrm{X}$ & & & & $\mathrm{X}$ & $\mathrm{X}$ & & & & \\
\hline Keay-Bright, 2007a, 2007b & $\mathrm{X}$ & & & & & & & & & & & & & & PD & & $x$ & & & & $x$ & & & & $\mathrm{x}$ & ENJ; CO; CS; SS^^ \\
\hline Larsen \& Hedvall, 2012 & & & & & $\mathrm{X}$ & & & & & & & & & & & & $\mathrm{X}$ & & & & & & & & & \\
\hline López-Mencía et al., 2010 & & & & & & & & & & & $\mathrm{X}$ & & & & $\mathrm{CO}$ & & $\mathrm{X}$ & & & & & & & & $\mathrm{X}$ & $E N J^{\wedge}$ \\
\hline Madsen et al., 2009 & & $\mathrm{X}$ & & & & & & & & & & & & & PD & & $\mathrm{X}$ & & & & & & & $\mathrm{X}$ & & \\
\hline
\end{tabular}




\begin{tabular}{|c|c|c|c|c|c|c|c|c|c|c|c|c|c|c|c|c|c|c|c|c|c|c|c|c|c|c|}
\hline \multirow[b]{2}{*}{ Article } & \multicolumn{14}{|c|}{ SEN and/or Disability of children } & \multirow[b]{2}{*}{$\begin{array}{l}\text { Design } \\
\text { approach }\end{array}$} & \multicolumn{3}{|c|}{$\begin{array}{l}\text { Technology } \\
\text { type }\end{array}$} & \multicolumn{5}{|c|}{$\begin{array}{l}\text { Children's role in design } \\
\text { process }\end{array}$} & \multicolumn{2}{|c|}{$\begin{array}{c}\text { Children's } \\
\text { impact on } \\
\text { tech. }\end{array}$} & \multirow[b]{2}{*}{$\begin{array}{l}\text { Outcomes of } \\
\text { participation for } \\
\text { children }\end{array}$} \\
\hline & 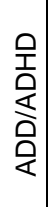 & 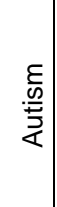 & 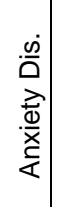 & 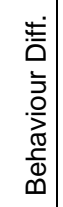 & 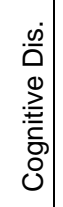 & 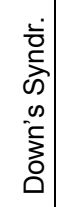 & $\begin{array}{l}\frac{\tilde{d}}{\widehat{x}} \\
\frac{\mathbb{d}}{\tilde{D}} \\
\widehat{\partial}\end{array}$ & 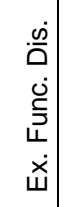 & 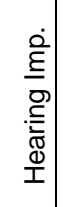 & 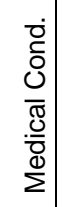 & $\begin{array}{c}\bar{D} \\
\Phi \\
\Phi \\
\frac{\mathscr{d}}{0} \\
\stackrel{\frac{J}{\alpha}}{a}\end{array}$ & के & 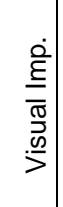 & 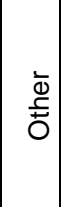 & & 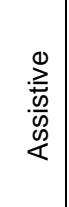 & 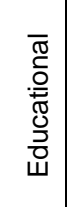 & 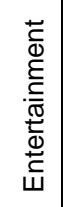 & $\begin{array}{l}\stackrel{\mathscr{N}}{\Phi} \\
\stackrel{\mathscr{D}}{\supset}\end{array}$ & 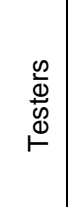 & 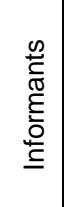 & 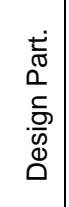 & $\begin{array}{l}\bar{\Phi} \\
\overline{0} \\
\overline{0} \\
\overline{0} \\
0 \\
\dot{1} \\
0\end{array}$ & 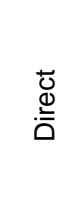 & 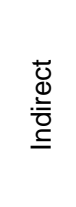 & \\
\hline Malinverni et al., 2014 & & $\mathrm{X}$ & & & & & & & & & & & & & PD & & $\mathrm{X}$ & & & & & $\mathrm{X}$ & & $\mathrm{X}$ & & ENJ; PR; FoC; ENG* \\
\hline Mazzone et al., 2008 & & & & $x$ & & & & & & & & & & & PD & & $x$ & & & & $x$ & & & $x$ & & $\begin{array}{l}\text { ENJ; OW; FoC; RE; } \\
\text { IB; ENG; CS; TS; NS* }\end{array}$ \\
\hline $\begin{array}{c}\text { McElligott \& van Leeuwen, } \\
2004\end{array}$ & & & & & & & & & & & & & $x$ & & $\ln D$ & & $x$ & & & & & & $x$ & & & ENJ; CO; PR; ENG^ \\
\hline Millen et al., 2010 & & $\mathrm{X}$ & & & & & & & & & & & & & $\mathrm{PD}$ & & $\mathrm{X}$ & & & & $\mathrm{X}$ & & & & & $E N J^{\wedge}$ \\
\hline Millen et al., 2011 & & $\mathrm{X}$ & & & & & & & & & & & & & SBD & & $\mathrm{X}$ & & & & & & & & & \\
\hline Parsons \& Cobb, 2014 & & $\mathrm{X}$ & & & & & & & & & & & & & PD & & $x$ & & & & $\mathrm{X}$ & & & & & $E N J^{\wedge}$ \\
\hline Piper et al., 2006 & & $x$ & & & & & & & & & & & & & & & $\mathrm{x}$ & & & & $\mathrm{X}$ & & & & & ENJ; CO; SS^ \\
\hline Potter et al., 2011 & & & & & & & & & $\mathrm{X}$ & & & & & & UCD & & $x$ & & $\mathrm{X}$ & & $\hat{x}$ & & & & & $\mathrm{ENJ}^{\wedge}$ \\
\hline Rigby et al., 2006 & & & & & & & & & & & $\mathrm{X}$ & & & & $\mathrm{CC}$ & $\mathrm{X}$ & & & & & & & & & & $\mathrm{CO}^{\wedge}$ \\
\hline Ruland et al., 2008 & & & & & & & & & & $\mathrm{X}$ & & & & & PD & $\mathrm{x}$ & & & & $\mathrm{X}$ & $\mathrm{X}$ & & & & & \\
\hline Sampath et al., 2013 & & $\mathrm{X}$ & & & & & & & & & & & & & PDwP & $\mathrm{x}$ & & & & & & & & & & \\
\hline Sánchez \& Flores, 2004 & & & & & & & & & & & & & $\mathrm{X}$ & & & & $\mathrm{X}$ & & & $\mathrm{X}$ & & & & & & $E \mathrm{ENJ}^{\wedge}$ \\
\hline Slegers et al., 2010 & & & & & & & & & $\mathrm{X}$ & & & & & & UCD & & & & & & & & & & & $\mathrm{CS}^{*}$ \\
\hline Tarrin et al., 2006 & & & & & & & & & & $\mathrm{X}$ & & & & & $\mathrm{CO}$ & $\mathrm{X}$ & & & & & & & $\mathrm{X}$ & & & $E N J^{\wedge}$ \\
\hline Van Rijn \& Stappers, 2008 & & $\mathrm{x}$ & & & & & & & & & & & & & PD & & $\mathrm{x}$ & & & & & & & & & \\
\hline Wärnestål et al., 2014 & & & & & & & & & & $\mathrm{X}$ & & & & & UCD & $\mathrm{X}$ & & & & $\mathrm{X}$ & $\mathrm{X}$ & & & $\mathrm{X}$ & & \\
\hline Zarin \& Fallman, 2011 & & $\mathrm{X}$ & & & & $\mathrm{X}$ & & & & & & & & & $\mathrm{ItD}$ & & $\mathrm{X}$ & & & & & & & & $\mathrm{X}$ & $E N J^{\wedge}$ \\
\hline
\end{tabular}

\section{Table 1 - Summary of all articles included within this review (shaded cells indicate information not specified in article)}

\begin{tabular}{|c|c|c|c|}
\hline Key to Design Approach & & Key to Outcomes of Participation & \\
\hline $\begin{array}{l}\text { InD - Informant Design } \\
\text { ItD - Iterative Design } \\
\text { InD - Inclusive Design } \\
\text { UCD - User-Centred Design } \\
\text { CC - Client-Centred } \\
\text { CO - Co-Design }\end{array}$ & $\begin{array}{l}\text { PD - Participatory Design } \\
\text { PDwP - Participatory Design with proxy } \\
\text { CI - Cooperative Inquiry } \\
\text { ECD - Experience-Dentred Design } \\
\text { SBD - Scenario-Based Design }\end{array}$ & $\begin{array}{l}\text { ENJ - Enjoyment } \\
\text { EM - Empowerment } \\
\text { CO - Confidence } \\
\text { ENG - Engagement } \\
\text { CS - Creativity Skills } \\
\text { TW -Team Work } \\
\text { SS - Social Skills } \\
\text { SE - Self-Efficacy } \\
\text { OW - ownership }\end{array}$ & $\begin{array}{l}\text { FoC - Feelings of Competence } \\
\text { PR - Pride } \\
\text { RE - Responsibility } \\
\text { IB - Improved Behaviour } \\
\text { TS - Technology-related Skills } \\
\text { NS - Narrative Skills } \\
\text { Outcomes resulting from: } \\
\wedge=\text { prototype use } \\
*=\text { design process }\end{array}$ \\
\hline
\end{tabular}


Many of the projects were targeted at a specific special educational need or disability but there were a subset of projects that involved a mix of children with different needs or individual children who had more complex needs. Table 2 provides an overview of the range of diverse needs covered by the projects using the four areas of need defined by the Departments of Education and Health, referred to in section 2.

\begin{tabular}{|l|l|}
\hline Communication and interaction & (Benton et al., 2012, 2014; Benton \& Johnson, 2013; Foss et al., \\
\hline Autism spectrum condition/disorder & 2013; Frauenberger et al., 2013, 2010, 2011; Grawemeyer et al., \\
(ASC/ASD) & 2012; Hourcade et al., 2012; Keay-Bright, 2007b, 2007a; Madsen et \\
& al., 2009; Malinverni et al., 2014; Millen et al., 2010, 2011; Parsons \& \\
& Cobb, 2014; Piper et al., 2006; Sampath et al., 2013; van Rijn \& \\
& Stappers, 2008; Zarin \& Fallman, 2011) \\
\hline Cognition and learning & (Al-Wabil et al., 2010; Benton et al., 2014; Foss et al., 2013) \\
\hline $\begin{array}{l}\text { Specific learning difficulties (SpLD) including } \\
\text { dyslexia }\end{array}$ & (Zarin \& Fallman, 2011) \\
\hline Down's syndrome & (Larsen \& Hedvall, 2012) \\
\hline Profound cognitive disabilities & (Guha, Druin, \& Fails, 2008) \\
\hline Executive function disorder & (Foss et al., 2013; Guha et al., 2008) \\
\hline Social, emotional and mental health difficulties \\
\hline $\begin{array}{l}\text { Attention deficit (hyperactivity) disorder } \\
\text { (ADD/ADHD) }\end{array}$ \\
\hline Anxiety disorder & (Foss et al., 2013) \\
\hline Unspecified behavioural difficulties & (Gibson et al., 2002; Mazzone et al., 2008) \\
\hline Sensory and/or physical needs & (Allsop et al., 2009; de Faria Borges et al., 2014; Hernandez et al., \\
\hline Cerebral palsy & 2013; Hornof, 2009; López-Mencía et al., 2010; Rigby et al., 2006) \\
\hline \multicolumn{2}{|l|}{ (Rigby et al., 2006) } \\
\hline Spina bifida & (Rigby et al., 2006) \\
\hline Neuromuscular conditions & (Hussain, 2010) \\
\hline Amelia/Limb loss & (Sánchez \& Flores 2004; McElligott \& van Leeuwen 2004) \\
\hline Visual impairments & (Henderson et al., 2005; Iversen et al., 2007; Potter et al., 2011; \\
\hline Hearing impairments & Slegers et al., 2010) \\
\hline Medical syndromes/conditions & (Ruland et al., 2008; Wärnestål et al., 2014) \\
\hline Cancer & (Tarrin et al., 2006) \\
\hline Hospitalised children & (Brederode et al., 2005; Culén et al., 2013; Durrant et al., 2013; \\
\hline Other & Holone \& Herstad, 2013) \\
\hline Multiple and/or Complex Needs & children with SEND in technology design \\
\hline Table 2 - Overview of different types of needs within research projects involving \\
\hline
\end{tabular}

These projects defined the design approach they followed in a range of different ways including:

- Participatory Design (Benton et al., 2012, 2014; Benton \& Johnson, 2013; de Faria Borges et al., 2014; Frauenberger et al., 2013, 2010, 2011; Frauenberger, Good, Alcorn, \& Pain, 2012; Hernandez et al., 2013; Holone \& Herstad, 2013; Hussain, 2010; Iversen et al., 2007; Keay-Bright, 2007a, 2007b; Madsen et al., 2009; Malinverni et al., 2014; Mazzone et al., 2008; Millen et al., 2010; Parsons \& Cobb, 2014; Ruland et al., 2008; van Rijn \& Stappers, 2008);

- Co-Design (Hornof, 2009; López-Mencía et al., 2010; Tarrin et al., 2006);

- Informant Design (Al-Wabil et al., 2010; Brederode et al., 2005);

- Experience-centred Design (Durrant et al., 2013);

- User-centred Design (Allsop et al., 2009; Culén et al., 2013; Potter et al., 2011; Slegers et al., 2010; Wärnestål et al., 2014);

- Client-Centred (Rigby et al., 2006);

- Inclusive Design (McElligott \& van Leeuwen 2004);

- Iterative Design (Henderson et al., 2005; Zarin \& Fallman, 2011);

- Scenario-based Design (Millen et al., 2011)

- Specific PD methods such as Cooperative Inquiry (Foss et al., 2013; Gibson et al., 2002; Grawemeyer et al., 2012; Guha et al., 2008);

- Unspecified (Hourcade et al., 2012; Larsen \& Hedvall, 2012; Piper et al., 2006; Sánchez \& Flores, 2004). 
The numbers of child participants with SEND and the length of time they were involved also varied from a single child (e.g. de Faria Borges et al., 2014; Potter et al., 2011) to 80+ (e.g. Rigby et al., 2006) and from one-off design sessions (e.g. Allsop et al., 2009) to multiple sessions over several months (e.g. Mazzone et al., 2008) or even years (e.g. Parsons \& Cobb, 2014). However, the number of child participants with SEND was typically under 10 and the number of design sessions five or less, with several papers not specifying the exact number of sessions that were conducted.

Some of the projects described in the literature focused purely on the methodology of involving children with SEND in the technology design process and therefore did not discuss the outcome of this involvement. However, others did describe, to varying degrees, how the children's involvement had informed the design of a new technology. These technology outcomes can be divided into three categories:

- Assistive Technology - e.g. communication devices (de Faria Borges et al., 2014; Hornof, 2009; Sampath et al., 2013; Tarrin et al., 2006), support systems (Ruland et al., 2008; Wärnestål et al., 2014), rehabilitation devices (Allsop et al., 2009), pupil consultation software (Gibson et al., 2002), seating systems (Rigby et al., 2006).

- Educational Technology - e.g. creative play and expression (Durrant et al., 2013; Holone \& Herstad, 2013; Hourcade et al., 2012; Keay-Bright, 2007a, 2007b; Larsen \& Hedvall, 2012; McElligott \& van Leeuwen, 2004) language/literacy (Al-Wabil et al., 2010; Benton et al., 2014; Iversen et al., 2007; van Rijn, 2012), mathematics (Benton et al., 2012, 2014; Benton \& Johnson, 2013; Grawemeyer et al., 2012; Sánchez \& Flores, 2004), sign language (Henderson et al., 2005; Potter et al., 2011), emotions/social skills (Brederode et al., 2005; Frauenberger et al., 2013, 2010, 2011; Frauenberger, Good, Keay-Bright, et al., 2012; Madsen et al., 2009; Malinverni et al., 2014; Mazzone et al., 2008; Millen et al., 2010, 2011; Parsons \& Cobb, 2014; Piper et al., 2006; Zarin \& Fallman, 2011) as well as unspecified educational software tools (Culén et al., 2013; López-Mencía et al., 2010).

- Entertainment Technology - e.g. non-educational games (Foss et al., 2013), exergames (Hernandez et al., 2013)

- Unspecified - (Guha et al., 2008; Hussain, 2010; Slegers et al., 2010).

\subsection{Previously defined roles of children with SEND in the technology design process}

Several researchers have specifically considered the roles of children with SEND. Hussain (2010) has used both Hart's ladder of participation and Druin's levels of involvement as inspiration for her Design Participation Ladder, which is intended to represent the participation of disadvantaged children in developing countries. The ladder includes three levels of participation, Included where the adults just observe the children and may ask basic questions of them; Consulted where the children are not directly involved in the design but are asked in appropriate ways to establish their requirements and preferences; and Empowered where the children have an influence on the design and are given the opportunity to learn skills and participate in developing solutions.

Frauenberger et al. (2012a) have adapted Arnstein's Ladder of Citizen Participation (which Hart's ladder is based upon) to apply to the participation of children with disabilities in the design process. They define three styles of participation which include Non-participatory where theories, best practices or previous experiences guide the design process;

Participation via proxy where a parent, carer or teacher participates on behalf of the child; and Full participation where the children are given the opportunity to have a direct impact on the design process, which has parallels with the Empowered role as defined by Hussain. However, this still does not consider exactly what this opportunity provides such as the specific activities the children are involved in.

Keay Bright (2007a, 2007b) has defined the role of Key Informant, which she specifically applied to the inclusion of children with low-functioning autism in the design process. This role allows the children to make contributions throughout the design process, which had a "significant impact on both the process and outcomes of the research" although the ultimate responsibility for the decision-making lies with the adult (Keay-Bright 2007b). Due to the limited communication abilities of the child participants this role appears to draw more 
parallels with the tester role as the children provide input into the design process through their interaction with a series of rapid 'suck it and see' prototypes, but do not engage in a direct dialogue with the adults (due to severe communication difficulties). However, Keay-Bright 2007a) explicitly states that this is not solely the case and the intention of their involvement is to "find out what motivates them, what makes them feel valued and what unique characteristics they possess that might not otherwise have been discovered" moving the level of involvement beyond that of solely a tester role.

The above suggests that the definitions and observer interpretations of the level of involvement of a child with SEND may differ to a child without SEND as, for instance, if a child has the appropriate level of communication skills then not asking them directly may severely restrict their level of involvement, but if this is not an option other alternative approaches need to be explored to enable their contribution. de Faria Borges et al. (2014) also highlight the issue concerning a child's active participation through their work with a young girl with severe cerebral palsy where there were severe difficulties for the child to engage in a dialogue with the adults about the technology design itself. They concluded that the child participant "was as active as any other team member because she provided the peculiar knowledge she possessed about herself and her capacities and limitations" even though this may not have been as detailed and specific as the contributions the adult team members were able to make.

Previous projects involving children with SEND, outlined in this review, have typically used Druin's classification of roles to define the child participants involvement in the technology design process, with projects involving children as:

- Users (Potter et al., 2011);

- Testers (Durrant et al., 2013; Frauenberger et al., 2013; Potter et al., 2011; Ruland et al., 2008; Sánchez \& Flores, 2004; Wärnestål et al., 2014);

- Informants (also defined as key informants or native informants) (Al-Wabil et al., 2010; Brederode et al., 2005; Culén et al., 2013; Frauenberger et al., 2013, 2010, 2011; Frauenberger, Good, Keay-Bright, et al., 2012; Hornof, 2009; Hussain, 2010; Iversen et al., 2007; Keay-Bright, 2007a; Mazzone et al., 2008; Millen et al., 2010; Parsons \& Cobb, 2014; Piper et al., 2006; Potter et al., 2011; Ruland et al., 2008; Wärnestål et al., 2014);

- Design Partners (Benton et al., 2012; Durrant et al., 2013; Foss et al., 2013; Frauenberger et al., 2013; Gibson et al., 2002; Grawemeyer et al., 2012; Guha et al., 2008; Holone \& Herstad, 2013; Iversen et al., 2007; Malinverni et al., 2014);

- Some authors used the more generic role of co-designer (de Faria Borges et al. 2014; McElligott \& van Leeuwen 2004; Tarrin et al. 2006)

- There were also some authors who did not explicitly define the level of involvement or role that the children undertook (Allsop et al., 2009; Benton \& Johnson, 2013; Benton et al., 2014; Henderson et al., 2005; Hernandez et al., 2013; Hourcade et al., 2012; Larsen \& Hedvall, 2012; López-Mencía et al., 2010; Madsen et al., 2009; Millen et al., 2011; Rigby et al., 2006; Slegers et al., 2010; van Rijn \& Stappers, 2008; Zarin \& Fallman, 2011).

It is interesting to note that within some papers the children undertook multiple roles (Durrant et al., 2013; Iversen et al., 2007; Potter et al., 2011; Wärnestål et al., 2014), with some authors choosing to redefine the children's role at different points in the design process, for instance switching between the informant and tester role. Although the role definition of informant actually encompasses the type of testing activities described within the tester role and so they could be viewed as acting as informants for the entirety of the process.

\subsection{Outcomes of involving children with SEND in the technology design process}

Read et al. (2014) describe the two traditions within the PD projects involving children which influence the way in which children's design contributions are generated and used within the technology design process, (i) to make better technology or (ii) for empowerment of the child participants. Therefore the outcomes of the design process can have varying levels of impact on both the resulting technology as well as the child participants themselves, depending on the level of the children's participation and how their design contributions are used. These 
design contributions are typically either the result of participation in small design teams over an extended period of time incrementally developing ideas (Guha, Druin, \& Fails, 2013) or larger numbers of children participating in short bursts to capture many ideas as an inspiration for designers (Mazzone, livari, Tikkanen, Read, \& Beale, 2010).

\subsubsection{Impact of participation on resulting technology}

One key aspect of the PD process is how the children's contributions actually inform the resulting technology design and as Frauenberger et al. (2012) highlight this is frequently an under-reported part of the process with many papers focusing predominantly on the method of involvement rather than the outcomes. This is typically a complex process and designers are often working within a very constrained design space due to a multitude of technical, time, resource, and in the case of educational technology pedagogical constraints, which are outside of their control.

One of the key factors in determining the extent of impact child participants have on the resulting technology is the relationship between the child and adult design team members. As part of her definition of children's roles in the design of new technology Druin (2002) has defined a continuum of possibilities in how children can relate to adults (see Figure 2) which include offering indirect input e.g. by being observed using technology, offering direct verbal/written feedback e.g. on prototype technology, engaging in a dialogue with adults e.g. discussing a design idea they have, or elaborating on another design team member's idea (child or adult's).

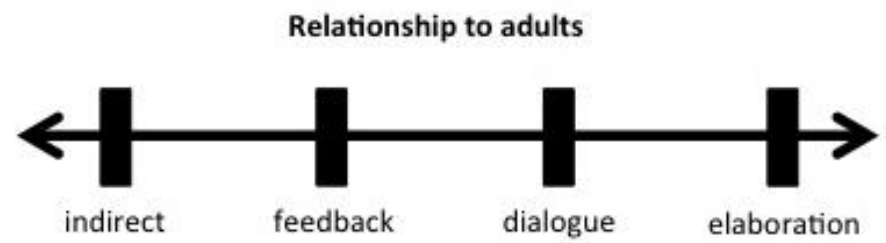

Figure 2 - An underlying dimension of children's role in the design of new technology as proposed by Druin (2002).

Where children are seen as design partners one of the most important aspects of the design process is idea elaboration, where both children and adults seek inspiration from each other's ideas. This inspiration is then used to create new ideas or design directions as well as build directly upon another participant's idea, where "ultimately it may be difficult to remember whose ideas they were originally" (Guha et al., 2013). A concern that has been raised about this process is the unequal power relationship between adults and children, making it difficult for idea elaboration to happen, which is particularly pertinent for children with SEND who spend much of their lives very much dependent on adults (Frauenberger et al., 2011). Techniques to redress this balance have been proposed by some researchers, such as one approach used by Guha et al. (2004) with young children aged 4-6 years in order to make the process of idea elaboration much more explicit. The approach involved iteratively combining individual ideas to allow the children to see how their ideas had influenced the final design and adults providing input at later stages of the process to help refine the ideas into a workable concept. There have also been concerns raised about the "power pendulum" swinging too far the other way, with adults being too worried about the children having a voice that they do not offer their own input (Guha et al., 2013).

When children have a less involved role within the design process adults often have more design input outside of the design sessions, deciding how to integrate the children's ideas into the final technology design. This makes the process much less transparent to the children, an issue pointed out by Read et al. (2014), and is often not reported in any detail within the literature, making it difficult to understand exactly what impact children's involvement has had on the final technology output. This is reflected in the SEND literature that has been reviewed for this paper, with many of the projects unclear about how the children's contributions were actually used (Al-Wabil et al., 2010; Allsop et al., 2009; Benton et al., 2012, 2014; Benton \& Johnson, 2013; Culén et al., 2013; Foss et al., 2013; Grawemeyer et al., 2012; Guha et al., 2008; Henderson et al., 2005; Holone \& Herstad, 2013; Hornof, 2009; Hourcade et al., 2012; 
Hussain, 2010; Iversen et al., 2007; Larsen \& Hedvall, 2012; McElligott \& van Leeuwen, 2004; Millen et al., 2010, 2011; Parsons \& Cobb, 2014; Piper et al., 2006; Potter et al., 2011; Rigby et al., 2006; Ruland et al., 2008; Sampath et al., 2013; Sánchez \& Flores, 2004; Slegers et al., 2010; Tarrin et al., 2006; van Rijn \& Stappers, 2008).

However, 14 projects did report at least some details of this process, which have been grouped into the different relationships children may have with adults (Druin, 2002) determining the nature of their design contributions: which include (i) Indirect (which provided both design inspiration and higher-level design values, goals and considerations); (ii) Feedback (iterating on design prototypes); (iii) Dialogue (generating design ideas); (iv) Elaboration (building on others' ideas).

Indirect - Providing design inspiration

In a subset of projects children had a relationship with adults which indirectly inspired the technology design in some way.

Within the ECHOES project, which aimed to create a technologically enhanced learning environment for developing social skills for children with and without autism, Frauenberger et al. (2010) describe the issues they experienced when working with child participants with autism. They state that the children "expressed their ideas in ways that would not allow us to simply transfer them into our design" and they were also "heavily biased by their immediate experiences, memories, television, games, together with environmental knowledge". However, they found looking instead at a level above the literal meanings of the design ideas, and identifying the fundamental phenomenological qualities within the ideas that this inspired a number of design concepts that could in turn be incorporated within the ECHOES environment. For example taking an idea in which a swimming pool and a tree house can turn into a mouse and person respectively, they extracted the concept of inanimate objects transforming into living things. The authors describe how the adult members of the design team used these concepts along with contextual information gained from their PD sessions, such as knowledge about the school environment and the children's behaviours and preferences in relation to earlier versions of the prototype, during a two-day design workshop to inform the design of the final ECHOES system.

Within the PD4CAT project, which aimed to design a communication device for improving language skills of non-verbal children, researchers faced different challenges when working with a four year old girl with cerebral palsy who experienced severe communication difficulties and was unable to initiate any design ideas of her own (de Faria Borges et al., 2014). Therefore during the early phases of their design process they used their observations and interactions with the child and her caregivers to inspire requirements for a customized assistive technology solution, which the child was then involved in refining further. They also later involved the same girl in paper prototyping sessions to establish her preferences for shape, colour, interaction and organization of the interface.

In addition to these projects López-Mencía et al. (2010) made specific changes to their interactive learning tool as a result of involving children with cerebral paralysis in the initial evaluation of their prototype design, such as increasing the size of particular interface features which they observed the children not paying attention to. In the Reactive Colours project Keay-Bright (2007b) followed a rapid 'suck it and see' approach to the design process, iterating on the prototype for the ReacTickles software aimed at encouraging spontaneous play for children with autism and observing children with low functioning autism interacting with the prototype at each stage to inform the design of the next iteration. Lastly Zarin and Fallman (2011) involved children with autism and Down's syndrome in a iterative ideation and prototyping process for designing their social communication skill-based micro-applications, which inspired new ideas and resulted in the constructions of more than 20 prototype micro applications.

Indirect - Defining design values, goals and considerations A number of projects also discuss design values, goals or considerations as an outcome of design sessions involving child participants with SEND, which are in turn used to inform or guide the design of the final technology output. 
For instance again within the ECHOES project Frauenberger et al. (2012) developed a set of values or 'must-haves' based on their experiences of working with children with autism that they believed the final design should embody, which included properties such as exploration, repetition, rhythm and playfulness. These values can have implications for the design of the environment aesthetics as well as the interaction. In later work on the same project the authors discuss how involving children with autism in a number of design critique sessions using a technological annotation tool resulted in several 'design triggers', informing for example the behaviours of characters or the mood of the scene, which would have been used to further improve the final technology had time allowed (Frauenberger et al., 2013).

As part of the pOwerball project, which aimed to design a novel augmented reality computer game for children with and without physical or learning disabilities, Brederode et al. (2005) involved children with learning difficulties and physical disabilities at a preliminary stage in the design process through interviews and observed them interacting with existing games. This resulted in a set of four design goals which guided the development of their game concept and included: Equalizing effect and competition; Participation and dialogue; Fun; and the 'Cool' factor.

Durrant et al. (2013) present a project with the intention of designing digital photographic tools for supporting interpersonal communication and expression within a mixed special educational needs classroom. They involved children with a range of complex special needs in an experience-centred design process that involved a number of creative photography workshops, and which resulted in a set of design considerations for supporting interpersonal communication and expression that was then used to inform the design of their tool. For instance through the workshops it became clear that the children often used their photos to represent their personal achievements and therefore one of the design considerations was to "support photo annotation and storytelling around photos for recognizing personal achievements".

\section{Feedback}

Several of the projects involved children with SEND in the evaluation of initial prototypes, providing feedback which then directly informed the further development of the prototype, including some of the projects already discussed above.

Durrant et al. ( 2013) took the digital photographic tool they developed as a result of the creative photography workshops back into the special education needs school to get the children's feedback, with some children suggesting specific design ideas such as novel forms for the magic wand included within the tool which the designers implemented as a result. Mazzone et al. (2008) involved teenagers with behavioural problems who had been excluded from mainstream education in the design of an application for improving emotional intelligence. They showed prototypes of the application to the teenagers involved in the design process and made a number of changes as a result of their feedback, including updating the language used within various aspects of the system as well as the look of the interface such as the hairstyle and facial expressions of the characters. The teenagers were also provided with the opportunity to voice the characters.

Gibson et al. (2002) involved children with and without behavioural problems within a design team where they iterated on their pupil consultation software prototype on a weekly basis and made changes based on the suggestions of the children with behavioural problems which included the addition of a customizable helper character that had characteristic interactive qualities, such as a wizard being about to make spells. Madsen et al. (2009) involved children with autism in the initial evaluation of their facial recognition software prototype, with the children's feedback helping to improve the design of the hardware, GUI and user experience. Hernandez et al. (2013) involved children with cerebral palsy in the design of action-based exergames. As part of this they conducted an 8 week home trial with a youth with cerebral palsy and gathered feedback to identify areas for redesign through questionnaires and interviews. 
Lastly Parsons and Cobb (2014) discuss the difficulty they had in incorporating some of the feedback they received from children with autism during the evaluation of an early prototype of their collaborative technology for teaching collaboration and social conversation. The children's preferences for being able to explore the virtual environment openly conflicted with the teacher's wish for a more constrained environment to prevent the children becoming distracted from their learning. In this case the designers chose to go with the teacher's idea, which resulted in some of the most able students becoming bored or frustrated with the more constrained activity.

\section{Dialogue}

Within some projects researchers reported being able to use children's ideas directly, although the choice of design ideas to incorporate was often subject to an assessment of suitability in terms of learning goals as well as technical and resource constraints.

Malinverni et al. (2014) discuss a project which aimed to design a motion-based game for developing social initiation skills, where they involved children with autism within the design process. The children participated in a set of five workshops, which were guided by a narrative structure and had a specific aim in terms of the aspect of the game design it was intended to inform. The authors generally did not provide the exact details of the ideas the children generated. They do however describe at a high-level how the ideas were included, stating that the children's ideas informed the game character's behaviour, game mechanics and interactions as well as the visual and narrative aspects. They used the previously defined learning goals as well as technological constraints to form a set of criteria that they then used to select which design concepts to use. It appeared that, in some design sessions at least, the children generated ideas individually rather than as a team, and the authors discussed the difficulty in integrating these highly different concrete design proposals.

Mazzone et al. (2008) also involved the teenagers with behavioural problems in a series of design sessions, with the design ideas informing the design of the scenarios, content and language included within the initial prototype of their emotional intelligence application, which they then further informed during later sessions

During the design of an action-based exergame children with cerebral palsy also participated in brainstorming sessions and "provided ideas of games and drawings of characters", which were then adapted and included in the final version of the game (Hernandez et al., 2013). However, it was not explained what these ideas were or how they were "adapted".

\section{Elaboration}

Few projects described children directly informing the technology design through elaboration on the ideas of others. However, in a project aiming to develop health-promoting services for children recovering from cancer Wärnestål et al. (2014) describe a set of design workshops where adult designers collaborated in pairs with children, who had been previously diagnosed with cancer, to design child personas that could be integrated into a digital-peer support service. The authors then describe how all of these design ideas were fed into a qualitative analysis in which they grouped the ideas into 40 categories and eight high-level themes. These in turn informed the design of the final high-quality personas. Although again they did not go into the details of the exact ideas the children generated and how the children and adults built on one anothers' ideas. Additionally in the design process of their motion-based game Malinverni et al. (2014) discuss the children not liking the researcher's idea for the game world being a jelly world and the children instead proposing an alternative urban environment. Lastly in the design of their mathematics-based games Benton et al. (2012) describe children with autism building on one another ideas and working collaboratively with adults and compromising with team members to agree final ideas. They also describe specific ideas that the children had which were incorporated in the prototype games such as the use of a storyline as part of the reward scheme and the use of weather to represent feedback. However, the process of elaboration of others' ideas is not explained in any detail.

In summary, the process of integrating the design contributions of children with SEND into a technological output described in these projects highlights a number of potential issues. The papers discuss several constraints on the inclusion of specific design ideas including 
technical, resource and pedagogical. Within some projects the children appear to work individually either due to the setup of the sessions or the children's difficulty with collaborative work. Thus designers are challenged with integrating often quite distinct ideas into a single coherent design. Many children with SEND can have problems communicating their design contributions, with adults needing to provide additional support to allow them to make their contributions and the children are therefore reliant on this support to be appropriate for their design contribution to be interpreted in the way that they intended. A further challenge, previously identified by Frauenberger et al. (2012), is in "faithfully representing input from participants" while recognizing the value of the adult design team members, which can be a difficult balance to strike especially when the focus is on ensuring that children with SEND are being given a voice. This is exemplified in the Parsons and Cobb (2014) paper referred to above where there were pedagogical constraints that led to difficult design choices. Clearly, the designers adhering to the teachers' wishes has the potential to directly impact on the children's experience of being part of a design team, where there is clear evidence of conflict in decision making and a power imbalance between children and adults.

\subsubsection{Impact of participation on the child participants}

PD is thought to offer a number of benefits to the participants through the process of mutual learning and opportunities for empowerment. These benefits are also referred to as 'user gains' (Bossen et al. 2010, 2012), and the question of whether this refers to the participants gaining from the improved output of the design process or from the actual participation in the process has recently been raised (Vines et al., 2012). It can be very difficult to empirically measure these benefits as it is not known if they have occurred as a direct result of participation or due to other reasons related to the external environment. It is also difficult to determine if some of these benefits may only be applicable in the short term or if involvement in the PD process can have lasting long-term benefits. Researchers who are focused on involving children in the design process have highlighted the importance of exploring the impact on children who participate in the technology design process (Guha, Druin, \& Fails, 2010). They suggest that qualitative approaches are most appropriate for measuring this type of impact, but admit this can be a 'messy' process.

The levels of participation or involvement in the technology design process can have an impact on the potential benefit a child may derive from their participation. For instance if a child undertakes a less involved role where they have a minimal impact on the final technology they are less likely to have feelings of empowerment or have had the opportunity to develop many skills. The specific role played by the child within the technology design process therefore has implications when considering the benefits of participation. However, due to the difficulties described above in measuring these beneficial impacts evidence gathered to date is often quite limited, informal and subjective.

Within the PD literature involving children with SEND a variety of benefits have been informally reported, which have resulted from either participation in early design activities as well as through interaction with initial prototypes of the technology. However, there has been no systematic investigation, monitoring or evaluation of these beneficial impacts, so it is unknown if all children experienced these and the extent to which these impacts persisted after the children's involvement came to an end.

Eleven projects explicitly reported a number of different beneficial impacts from participating in early design activities such as idea generation and refinement as well as low-tech prototyping. The reported beneficial impacts included enjoyment, gaining a sense of empowerment, feeling a sense of ownership or pride, taking on more responsibility, improved behaviour, increased engagement, increased confidence, feelings of competence, developing creativity skills as well as developing team work and social skills. These reported impacts came from a number of sources including:

- Researcher observations (Allsop et al., 2009; Foss et al., 2013; Frauenberger et al., 2013; Gibson et al., 2002; Grawemeyer et al., 2012; Hornof, 2009; Hussain, 2010; Malinverni et al., 2014); 
- Teacher (or other experts familiar with the children) reports gathered from questionnaires (Benton et al., 2012; Benton \& Johnson, 2013)and informal evaluations/consultations (Mazzone et al., 2008; Slegers et al., 2010);

- Self report from children gathered from questionnaires (Benton et al., 2012; Benton \& Johnson, 2013; Mazzone et al., 2008) and informal evaluations (Mazzone et al., 2008).

Thirteen different projects reported beneficial outcomes to the children involved in evaluating early versions of the prototype technology. Again these benefits were reported from a number of sources including:

- Researcher observations (Durrant et al., 2013; Hourcade et al., 2012; López-Mencía et al., 2010; Parsons \& Cobb, 2014; Potter et al., 2011; Rigby et al., 2006; Sánchez \& Flores, 2004; Tarrin et al., 2006);

- Teacher/other expert observations/verifications gathered from questionnaires (KeayBright, 2007a, 2007b), interviews (Piper et al., 2006), video footage analysis (KeayBright, 2007a) and informal evaluations (McElligott \& van Leeuwen, 2004);

- Self report from children gathered from informal evaluations (Millen et al., 2010; Zarin \& Fallman, 2011) and interviews (Hernandez et al., 2013).

Some of these benefits occurred partly due to the nature of technology itself, for example Piper et al. (2006) report improvements in social skills in the children with autism they involved in the evaluation of their tabletop game for social skills development.

The table below provides an overview of the various reported beneficial outcomes for children with SEND participating in early design activities and/or initial prototype evaluation, the source of evidence for this outcome and the article(s) these outcomes were reported in. 


\begin{tabular}{|c|c|c|c|}
\hline Reported benefit & $\begin{array}{l}\text { Stage of } \\
\text { design } \\
\text { process }\end{array}$ & Source & Article(s) \\
\hline \multirow[t]{8}{*}{ Enjoyment } & \multirow[t]{3}{*}{$\begin{array}{l}\text { Early design } \\
\text { activities }\end{array}$} & $\begin{array}{l}\text { Researcher } \\
\text { observations }\end{array}$ & $\begin{array}{l}\text { (Allsop et al., 2009; Foss et al., 2013; } \\
\text { Grawemeyer et al., 2012; Malinverni et al., } \\
\text { 2014; Mazzone et al., 2008) }\end{array}$ \\
\hline & & $\begin{array}{l}\text { Teacher report } \\
\text { (questionnaire) }\end{array}$ & (Benton et al., 2012; Benton \& Johnson, 2013) \\
\hline & & $\begin{array}{l}\text { Child self-report } \\
\text { (questionnaire) }\end{array}$ & $\begin{array}{l}\text { (Benton et al., 2012; Benton \& Johnson, 2013; } \\
\text { Mazzone et al., 2008) }\end{array}$ \\
\hline & \multirow[t]{5}{*}{$\begin{array}{l}\text { Initial } \\
\text { prototype } \\
\text { evaluation }\end{array}$} & $\begin{array}{l}\text { Researcher } \\
\text { observation }\end{array}$ & $\begin{array}{l}\text { (Hourcade et al., 2012; Keay-Bright, 2007a; } \\
\text { López-Mencía et al., 2010; McElligott \& van } \\
\text { Leeuwen, 2004; Parsons \& Cobb, 2014; Potter } \\
\text { et al., 2011; Sánchez \& Flores, 2004; Tarrin et } \\
\text { al., 2006) }\end{array}$ \\
\hline & & $\begin{array}{l}\text { Teacher report } \\
\text { (questionnaire) }\end{array}$ & (Keay-Bright, 2007a, 2007b) \\
\hline & & $\begin{array}{l}\text { Therapist report } \\
\text { (interview) }\end{array}$ & (Piper et al., 2006) \\
\hline & & $\begin{array}{l}\text { Child self report } \\
\text { (informal evaluation) }\end{array}$ & (Millen et al., 2010; Zarin \& Fallman, 2011) \\
\hline & & $\begin{array}{l}\text { Child self report } \\
\text { (interview) }\end{array}$ & (Hernandez et al., 2013) \\
\hline \multirow[t]{2}{*}{$\begin{array}{l}\text { Feeling a sense of } \\
\text { empowerment }\end{array}$} & \multirow[t]{2}{*}{$\begin{array}{l}\text { Early design } \\
\text { activities }\end{array}$} & $\begin{array}{l}\text { Researcher } \\
\text { observations }\end{array}$ & (Gibson et al., 2002; Malinverni et al., 2014) \\
\hline & & $\begin{array}{l}\text { Teacher report } \\
\text { (questionnaire) }\end{array}$ & (Benton et al., 2012; Benton \& Johnson, 2013) \\
\hline \multirow[t]{2}{*}{$\begin{array}{l}\text { Feeling a sense of } \\
\text { ownership/pride }\end{array}$} & $\begin{array}{l}\text { Early design } \\
\text { activities }\end{array}$ & $\begin{array}{l}\text { Researcher } \\
\text { observations }\end{array}$ & $\begin{array}{l}\text { (Foss et al., 2013; Hornof, 2009; Malinverni et } \\
\text { al., 2014; Mazzone et al., 2008) }\end{array}$ \\
\hline & $\begin{array}{l}\text { Initial } \\
\text { prototype } \\
\text { evaluation }\end{array}$ & $\begin{array}{l}\text { Researcher } \\
\text { observations }\end{array}$ & (McElligott \& van Leeuwen, 2004) \\
\hline \multirow[t]{3}{*}{$\begin{array}{l}\text { Feelings of } \\
\text { competence/self-efficacy }\end{array}$} & \multirow[t]{2}{*}{$\begin{array}{l}\text { Early design } \\
\text { activities }\end{array}$} & $\begin{array}{l}\text { Researcher } \\
\text { observations }\end{array}$ & $\begin{array}{l}\text { (Hussain, 2010; Malinverni et al., 2014; } \\
\text { Mazzone et al., 2008) }\end{array}$ \\
\hline & & $\begin{array}{l}\text { Teacher report } \\
\text { (through consultation } \\
\text { with researchers) }\end{array}$ & (Mazzone et al., 2008) \\
\hline & $\begin{array}{l}\text { Initial } \\
\text { prototype } \\
\text { evaluation }\end{array}$ & $\begin{array}{l}\text { Researcher } \\
\text { observations }\end{array}$ & (Durrant et al., 2013) \\
\hline \multirow[t]{5}{*}{ Increased confidence } & \multirow[t]{2}{*}{$\begin{array}{l}\text { Early design } \\
\text { activities }\end{array}$} & $\begin{array}{l}\text { Researcher } \\
\text { observations }\end{array}$ & (Benton et al., 2012; Benton \& Johnson, 2013) \\
\hline & & $\begin{array}{l}\text { Teacher report } \\
\text { (questionnaire) }\end{array}$ & (Benton et al., 2012; Benton \& Johnson, 2013) \\
\hline & \multirow{3}{*}{$\begin{array}{l}\text { Initial } \\
\text { prototype } \\
\text { evaluation }\end{array}$} & $\begin{array}{l}\text { Researcher } \\
\text { observations }\end{array}$ & $\begin{array}{l}\text { (McElligott \& van Leeuwen, 2004; Rigby et al., } \\
\text { 2006) }\end{array}$ \\
\hline & & $\begin{array}{l}\text { Therapist report } \\
\text { (interview) }\end{array}$ & (Piper et al., 2006) \\
\hline & & $\begin{array}{l}\text { Teacher report } \\
\text { (informal evaluation) }\end{array}$ & (McElligott \& van Leeuwen, 2004) \\
\hline $\begin{array}{l}\text { Taking on more } \\
\text { responsibility }\end{array}$ & $\begin{array}{l}\text { Early design } \\
\text { activities }\end{array}$ & $\begin{array}{l}\text { Researcher } \\
\text { observations }\end{array}$ & (Mazzone et al., 2008) \\
\hline Improved behaviour & $\begin{array}{l}\text { Early design } \\
\text { activities }\end{array}$ & $\begin{array}{l}\text { Researcher } \\
\text { observations }\end{array}$ & (Mazzone et al., 2008) \\
\hline \multirow[t]{6}{*}{$\begin{array}{l}\text { Increased engagement/ } \\
\text { concentration }\end{array}$} & \multirow[t]{3}{*}{$\begin{array}{l}\text { Early design } \\
\text { activities }\end{array}$} & $\begin{array}{l}\text { Researcher } \\
\text { observations }\end{array}$ & $\begin{array}{l}\text { (Benton et al., 2012; Benton \& Johnson, 2013; } \\
\text { Frauenberger et al., 2013; Malinverni et al., } \\
\text { 2014; Mazzone et al., 2008) }\end{array}$ \\
\hline & & $\begin{array}{l}\text { Teacher report } \\
\text { (informal evaluation) }\end{array}$ & (Mazzone et al., 2008) \\
\hline & & $\begin{array}{l}\text { Child self-report } \\
\text { (informal evaluation) }\end{array}$ & (Mazzone et al., 2008) \\
\hline & \multirow{3}{*}{$\begin{array}{l}\text { Initial } \\
\text { prototype } \\
\text { evaluation }\end{array}$} & $\begin{array}{l}\text { Researcher } \\
\text { observations }\end{array}$ & (McElligott \& van Leeuwen, 2004) \\
\hline & & $\begin{array}{l}\text { Teacher report } \\
\text { (questionnaire) }\end{array}$ & (Keay-Bright, 2007a, 2007b) \\
\hline & & $\begin{array}{l}\text { Development panelists } \\
\text { (video footage } \\
\text { analysis) }\end{array}$ & (Keay-Bright, 2007a) \\
\hline
\end{tabular}




\begin{tabular}{|c|c|c|c|}
\hline Reported benefit & $\begin{array}{l}\text { Stage of } \\
\text { design } \\
\text { process }\end{array}$ & Source & Article(s) \\
\hline \multirow{5}{*}{$\begin{array}{l}\text { Developing } \\
\text { creativity/imagination } \\
\text { skills }\end{array}$} & \multirow[t]{4}{*}{$\begin{array}{l}\text { Early design } \\
\text { activities }\end{array}$} & $\begin{array}{l}\text { Researcher } \\
\text { observations }\end{array}$ & $\begin{array}{l}\text { (Benton et al., 2012; Benton \& Johnson, 2013; } \\
\text { Mazzone et al., 2008) }\end{array}$ \\
\hline & & $\begin{array}{l}\text { Teacher report } \\
\text { (questionnaire) }\end{array}$ & (Benton et al., 2012; Benton \& Johnson, 2013) \\
\hline & & $\begin{array}{l}\text { Teacher report } \\
\text { (informal evaluation) }\end{array}$ & (Mazzone et al., 2008; Slegers et al., 2010) \\
\hline & & $\begin{array}{l}\text { Child self-report } \\
\text { (informal evaluation) }\end{array}$ & (Mazzone et al., 2008) \\
\hline & $\begin{array}{l}\text { Initial } \\
\text { prototype } \\
\text { evaluation }\end{array}$ & $\begin{array}{l}\text { Development panelists } \\
\text { (video footage } \\
\text { analysis) }\end{array}$ & (Keay-Bright, 2007a) \\
\hline \multirow[t]{4}{*}{$\begin{array}{l}\text { Developing team work } \\
\text { and social skills }\end{array}$} & \multirow[t]{2}{*}{$\begin{array}{l}\text { Early design } \\
\text { activities }\end{array}$} & $\begin{array}{l}\text { Researcher } \\
\text { observations }\end{array}$ & (Benton et al., 2012; Benton \& Johnson, 2013) \\
\hline & & $\begin{array}{l}\text { Teacher report } \\
\text { (questionnaire) }\end{array}$ & (Benton et al., 2012; Benton \& Johnson, 2013) \\
\hline & \multirow{2}{*}{$\begin{array}{l}\text { Initial } \\
\text { prototype } \\
\text { evaluation }\end{array}$} & $\begin{array}{l}\text { Therapist report } \\
\text { (interview) }\end{array}$ & (Piper et al., 2006) \\
\hline & & $\begin{array}{l}\text { Teacher report } \\
\text { (questionnaire) }\end{array}$ & (Keay-Bright, 2007a, 2007b) \\
\hline \multirow[t]{2}{*}{$\begin{array}{l}\text { Developing technology- } \\
\text { related skills }\end{array}$} & \multirow[t]{2}{*}{$\begin{array}{l}\text { Early design } \\
\text { activities }\end{array}$} & $\begin{array}{l}\text { Researcher } \\
\text { observations }\end{array}$ & (Mazzone et al., 2008) \\
\hline & & $\begin{array}{l}\text { Teacher report } \\
\text { (through consultation } \\
\text { with researchers) }\end{array}$ & (Mazzone et al., 2008) \\
\hline \multirow[t]{2}{*}{ Developing narrative skills } & \multirow[t]{2}{*}{$\begin{array}{l}\text { Early design } \\
\text { activities }\end{array}$} & $\begin{array}{l}\text { Researcher } \\
\text { observations }\end{array}$ & (Mazzone et al., 2008) \\
\hline & & $\begin{array}{l}\text { Teacher report } \\
\text { (through consultation } \\
\text { with researchers) }\end{array}$ & (Mazzone et al., 2008) \\
\hline
\end{tabular}

Table 3 - Reported beneficial outcomes for children with SEND participating in early design activities and/or initial prototype evaluation

In addition to the beneficial outcomes of participation Malinverni et al. (2014) stated that the children with autism that participated in their project did not enjoy all of the design activities; Parsons and Cobb (2014) highlighted the frustration and boredom experienced by some of the children with autism when interacting within their prototype technology; Foss et al. (2013) reported some confusion and/or boredom observed in some of the children with special learning needs involved in their design sessions; lastly Keay Bright (2007a) described some of the children with low-functioning autism who participated in early prototype evaluation sessions becoming upset at having to wait their turn to interact with the prototype. However, the majority of the papers focused solely on the positive impact of participation or did not discuss the impact on the children at all (Al-Wabil et al., 2010; Benton et al., 2014; Brederode et al., 2005; Culén et al., 2013; de Faria Borges et al., 2014; Frauenberger, Good, KeayBright, et al., 2012; Frauenberger et al., 2010, 2011; Guha et al., 2008; Henderson et al., 2005; Holone \& Herstad, 2013; Iversen et al., 2007; Larsen \& Hedvall, 2012; Madsen et al., 2009; Millen et al., 2011; Ruland et al., 2008; Sampath et al., 2013; van Rijn \& Stappers, 2008; Wärnestål et al., 2014).

Guha et al. (2010) highlight the importance of considering in advance the impact of involvement in the technology design process and state "ethically, it is the responsibility of researchers involved in technology design with children to ensure that the children involved are participating in a positive experience". Although some potentially negative impacts have been noted above, researchers should attempt to mitigate these negative experiences wherever possible. The review of the current literature has highlighted that positive outcomes of participation can occur to varying degrees and this is another important dimension of a child's role within the technology design process that can be overlooked, and is particularly essential to consider for children with SEND whose involvement would require more careful planning to ensure it is a positive one and also potentially have more to gain from their involvement. Therefore we propose this should form an additional continuum of possibilities to be considered alongside the existing underlying dimensions of children's roles in the design of new technologies originally set out by Druin (2002) (see also (Guha et al., 2013)). 


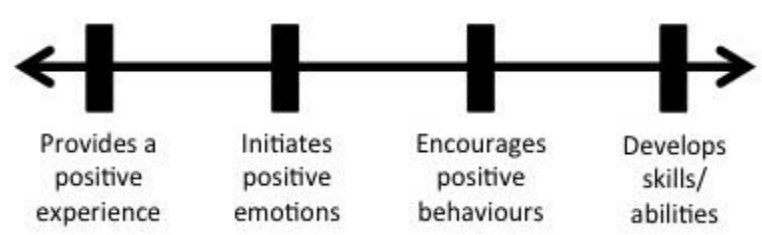

Figure 3 - Impact of participation in technology design process on children with SEND

Figure 3 presents the continuum of possibilities for the (positive) impact of the participation of children with SEND in the technology design process. The minimum expectation is that the participation would be a positive and enjoyable experience for the children. Participation might also initiate positive emotions in the children such as feeling a sense of empowerment or pride as well as feeling more competent or confident. Participating in certain design activities could encourage positive behaviours such as demonstrating increased responsibility or engagement. Lastly participation may have a more prolonged impact on the children providing them with the opportunity to develop skills such as creativity, social, team work, narrative and technical skills that could benefit them in other areas of their lives. It is important to note that the above continuum is an initial attempt to represent the positive impacts identified within the literature to date. However, these possibilities should not be seen as distinct, preferable to one another or encompassing the full spectrum and complexity of potential positive forms of impact.

\section{The role of the adult}

Within the child PD literature there has been more focus on the role of the children within the design process, than on the role of adults where there is not an equivalent set of discrete roles widely referred to in the literature. With respect to the roles of children many researchers have discussed these and classified children's participation using existing role definitions (e.g. Druin, 2002), as well as modifying existing roles or creating new roles for a specific project context. Although depicting the roles as either a ladder or a list of increasing participation has caused controversy, there are potentially benefits to describing children's involvement in PD in terms of discrete roles. The depicted roles connote responsibilities pertaining to those roles, the functions that the roles perform and the expected behavior patterns associated with them. This allows researchers to characterize PD sessions and allows predictions to be made related to the inherent responsibilities. Moreover, the roles are aligned specifically with activities undertaken as part of a design process: that is being observed using the software as (users); testing prototypes and providing feedback (testers); informing design solutions (informants) and having an equal opportunity to participate throughout (design partners). Defining a child's participation by a role label gives us an indication of their involvement and sets the context within which to view the final designed solution and its potential fitness for use by the targeted child population. The children's role therefore is dictated by their contribution to the design process and designed product per se.

This is not the case for adult participants where the role they have to play is multifaceted and the associated responsibilities, functions and actions to perform are wide ranging. Whilst they may contribute in many ways to a design process and designed artifact, their responsibilities do not end there. They are also specifically responsible for: i) ensuring the children's well being throughout the sessions; ii) ensuring that every opportunity and encouragement is given to the children for them to engage in the activities if they want to; iii) providing the support and environment for the children to feel empowered (where this is possible dependent on the child population); iv) providing an environment that fosters mutual learning following the PD tradition; and v) creating an experience that is positive enough for the children for them to want the experience to be repeated. The first of these necessitates the adult in providing care, protection, safety and avoiding neglect, whilst the others necessitate the adult in providing encouragement, in motivating and stimulating an interest in the activity, and facilitating by providing help and making contributing as easy as possible. Adults therefore, not only frequently engage in design activities but also activities inherent in the pursuance of the responsibilities given above. Whilst this list may not be exhaustive, it is clear that adhering to these responsibilities could well be of benefit to typically developing children 
along with those with SEND, in much the same way that engaging in universal design within $\mathrm{HCl}$ very often benefits all users not just those with cognitive, social or physical impairments.

Some of the responsibilities of the adult role outlined above, have been discussed on occasion in the PD literature. For instance Guha et al. (2013) describe instances during design sessions where adults undertake "typical adult responsibilities" in terms of facilitating the overall session (also highlighted by Nesset and Large (2004), Guha et al (2004) and Read et al. (2002)) and in acting as a "caregiver" to ensure a child's well-being is maintained throughout the session. Researchers have also previously discussed adults making their own design contributions or elaborating on other design team members' ideas during design sessions (Guha et al., 2004, 2013; Nesset \& Large, 2004; Read et al., 2002). Furthermore Guha et al. (2004) highlight adults providing encouragement for children during idea generation activities. Aside from the work mentioned above there has been quite limited discussion of adult roles within the child PD literature in general. Consequently, when researchers have involved children with SEND, there has been little existing literature to use as a basis for describing the different forms of involvement, and specific activities the adults undertook within these projects. Benton and Johnson (2013) have attempted to partly address this within their discussion regarding the roles of the various adults in the PD sessions they undertook with both children with autism and typically developing children. They used the identified responsibilities mentioned in the child PD literature discussed above, with the addition of further responsibilities to support the initiation of design contributions from the children and manage their behaviour. They then used these roles and responsibilities to code the adults' utterances during the sessions to identify how much structure and support the adults were required to provide the children during the design sessions.

Many technology design projects involving children without SEND involve small numbers of adults typically researchers and/or designers, from a range of backgrounds from education to computer science to graphic design (Guha et al., 2013) and also sometimes teaching staff if the sessions take place in the school environment (Good \& Robertson, 2006). In contrast projects involving children with SEND in the technology design process generally include a higher ratio of adults to child participants (Foss et al., 2013) and the adults can also come from an extremely wide range of backgrounds, with examples from the literature including:

- Researchers/Designers (typically all projects involved an adult from a research and/or design background);

- Parents and Caregivers (de Faria Borges et al., 2014; Frauenberger, Good, KeayBright, et al., 2012; Holone \& Herstad, 2013; Hornof, 2009; Hourcade et al., 2012; Piper et al., 2006; Potter et al., 2011; Rigby et al., 2006; Sampath et al., 2013; van Rijn \& Stappers, 2008; Zarin \& Fallman, 2011);

- Practitioners and Specialists - e.g. dyslexia practitioners (AI-Wabil et al., 2010), experts in hearing aids and cochlear implants (Slegers et al., 2010);

- Teaching Staff - e.g. aides (Guha et al., 2008; Hourcade et al., 2012), program coordinators (Hourcade et al., 2012), special education and class teachers (Benton et al., 2012, 2014; Benton \& Johnson, 2013; Brederode et al., 2005; Culén et al., 2013; de Faria Borges et al., 2014; Durrant et al., 2013; Foss et al., 2013; Frauenberger et al., 2013; Grawemeyer et al., 2012; Hourcade et al., 2012; Iversen et al., 2007; López-Mencía et al., 2010; Madsen et al., 2009; McElligott \& van Leeuwen, 2004; Millen et al., 2010; Parsons \& Cobb, 2014; Sánchez \& Flores, 2004; van Rijn \& Stappers, 2008; Zarin \& Fallman, 2011);

- Therapists - e.g. speech (Iversen et al., 2007; van Rijn \& Stappers, 2008), hearing (Iversen et al., 2007), social skills (Piper et al., 2006);

- Health Professionals - e.g. clinical assistants (Madsen et al., 2009), psychologists (Malinverni et al., 2014; Mazzone et al., 2008; Slegers et al., 2010), nurse (Hornof, 2009), hospital staff (Tarrin et al., 2006), speech-language pathologists (Hornof, 2009), clinical services providers (Rigby et al., 2006), pediatrician and physiotherapist (Hernandez et al., 2013);

- Support Workers - e.g. case workers (Mazzone et al., 2008), care professionals (van Rijn \& Stappers, 2008), sign language interpreter (Guha et al., 2008; Slegers et al., 2010), helpers (Holone \& Herstad, 2013). 
Involving more adults from a range of different backgrounds and with varying experiences of technology can bring added complexity to the design process, particularly in building relationships amongst participants, which can require time and empathy (Frauenberger, Good, \& Alcorn, 2012; Frauenberger et al., 2011). Previous literature on involving children with SEND in the technology design process varies in the level of detail explaining how the adults who are not researchers/designers have been introduced to the project and defining how they are expected to contribute towards the design process. However, many papers focus predominantly on the children's contribution, making it difficult to determine the impact each of the adults had on the final outcomes. The various backgrounds of the adults are discussed but their exact role and responsibilities within the project are never explicitly defined.

6.1 Roles, responsibilities and activities undertaken by adults when involving children with SEND in the technology design process

The different roles, responsibilities and activities undertaken by the adult participants within each of the technology design projects involving children with SEND have been examined and are discussed below. In keeping with our view of the wide ranging responsibilities of adults (outlined in the previous section), and in conjunction with the child PD literature discussed above as guidance, the identified roles, responsibilities and activities have been grouped according to whether they related to facilitation, motivation, caregiving or the adults contributing as a participant to the design process either as a proxy for the children or codesigning with them. Adults contributing as proxies is an important aspect to discuss in this paper as it occurs more frequently than for children without SEND due to the communication difficulties the children with SEND may experience, which can make it challenging for them to contribute their ideas directly. It should be noted that the roles, responsibilities and activities discussed below do not represent distinct roles that an adult would undertake throughout the technology design process, in the way that the roles of children as specified by Druin (2002) do. These are instead features that comprise the role an adult may potentially undertake, depending on the project context and the specific needs of the child participants, and which may evolve over the design process.

\subsubsection{Facilitation}

All of the projects involved adults undertaking facilitation-related activities to a certain extent as the researchers and/or designers had to coordinate the running of the design sessions, although the details of how this was undertaken were very limited in some of the papers. In terms of setting the design session agenda and structure, within some projects it was described how researchers had to ensure the sessions kept to time and followed the planned schedule (Wärnestål et al. 2014; Benton et al. 2012, 2014), as well as how they recapped previous sessions to ensure the children could remember what they had done from session to session and understood the progression of the design ideas (Gibson et al. 2002; Benton et al. 2012, 2014).

There were also examples of adults (typically the researcher/designer) providing additional explanations to help clarify any misunderstandings (Millen et al., 2011) as well as reminding the children of the task and/or repeating specific instructions (Benton et al., 2012; Foss et al., 2013; Millen et al., 2011). However, Slegers et al. (2010) highlight the difficulty of providing these oral explanations to the children they worked with who had hearing impairments and the requirement for a sign language interpreter to provide this support.

In many projects involving children with SEND there was little need to facilitate consensus as children often participated individually or were not required to agree on a single design vision as a team. This may have been due to the communication or social difficulties many children with SEND can experience. However, this did occur within some projects with researchers facilitating discussion amongst child participants (Benton et al., 2012; Benton \& Johnson, 2013; Foss et al., 2013; Grawemeyer et al., 2012) and in one case this was led by a therapist (Piper et al., 2006). Researchers and teachers also proactively orchestrated the selection and combining of groups to ensure they contained the most appropriate mix of children in terms of personality and ability (Durrant et al., 2013; Foss et al., 2013) and researchers would remind the children of the session rules such as raising of hands (Benton et al., 2012; Foss et al., 
2013) with teachers sometimes reinforcing expected classroom behaviours (Benton et al., 2012).

Adults helped to clarify children's ideas and opinions in various ways. In some projects where the children had sufficient communication skills the researchers and/or designers would directly interview them to find out (Brederode et al., 2005; Culén et al., 2013; de Faria Borges et al., 2014; Hernandez et al., 2013; Hussain, 2010; Piper et al., 2006; Ruland et al., 2008; Sánchez \& Flores, 2004) as well as ask them more open-ended questions during informal play (Frauenberger et al., 2011) or whilst interacting with a prototype of the technology (Frauenberger et al., 2013). The researchers and designers also helped to note down or draw out the children's ideas (Benton et al., 2012; de Faria Borges et al., 2014; Foss et al., 2013; Grawemeyer et al., 2012; Guha et al., 2008; Malinverni et al., 2014; Rigby et al., 2006). Furthermore Holone and Herstad (2013) describe child participants' ideas being presented back to the group verbally by a helper.

To enable progress during the sessions, the adults adopted a number of different strategies. In many projects they provide additional support to enable the children to successfully interact with prototypes of the technology. This support was provided by a range of adults including the researcher/designer (Brederode et al., 2005; Hourcade et al., 2012; Larsen \& Hedvall, 2012; López-Mencía et al., 2010; Millen et al., 2010; Sánchez \& Flores, 2004; Tarrin et al., 2006; Wärnestål et al., 2014) as well as a language scientist (de Faria Borges et al., 2014), the children's helper (Holone \& Herstad, 2013), parents (van Rijn \& Stappers, 2008), teacher (Keay-Bright 2007a, 2007b), therapist (Piper et al., 2006), and sign language facilitator (Henderson et al., 2005). The researcher/designer in some cases also helped any children who had difficulties with drawing, writing, reading or spelling (de Faria Borges et al. 2014; Millen et al. 2011; Benton et al. 2012, 2014) as well as provide example ideas to support children with initial idea generation (Mazzone et al. 2008; Hornof 2009; Benton et al. 2012, 2014) and discouraged negative behaviours that could prevent progress (Benton et al., 2012).

Two projects discussed introductory tasks that were undertaken by the children's teacher prior to the initial design sessions with the researchers/designers to prepare the children for the types of activity these sessions would involve (Rigby et al., 2006; Slegers et al., 2010).

Lastly Mazzone et al. (2008) discuss how they were required to explicitly instruct the psychologists within the design sessions they ran with teenagers with behavioural problems "to not intervene and to avoid trying to help the pupils deal with their emotions during design activities" which were directly related to these emotional issues. Interestingly, this was the only example that discussed the exact instructions given by the researchers/designers to the other adults within the team.

\subsubsection{Motivation}

A smaller sub-set of projects explicitly discussed an adult taking responsibility for motivating the children's engagement within the session. Within 8 projects this responsibility was generally undertaken by the researcher/designer leading the session but the knowledge of other adults more familiar with the children may have also be important to allow them to effectively motivate the children during the sessions.

Within some of the projects the researchers/designers provided praise or encouragement to the children. For example Gibson et al. (2002) encouraged the wacky ideas of the children with behavioural problems who they worked with to inspire other children to think 'outside of the box' in their idea generation. Madsen et al. (2009) encouraged the adolescents with autism they involved in usability testing to think of new ways that their facial recognition system could be used. Within some projects the provision of one-to-one adult support was discussed which was used to help certain children stay focused on the task and to prevent disengagement by linking to children's personal interests where possible (Benton et al., 2012; Guha et al., 2008). Benton et al. (2012) described how the researchers would reassure the children with autism they worked with that certain ideas could be changed when they became fixated on issues and disengaged from the task at hand as a result. In the same project Within the same Benton and Johnson (2013) state that the adults encouraged the children to share their ideas and praised any ideas that they generated, which helped build their 
confidence. They also describe how the adults explicitly prompted the children to contribute design ideas. Furthermore Mazzone et al. (2008) highlighted the need for the researchers to ensure that the teenagers they worked with understood the value in their efforts in order to maintain engagement throughout the design process.

Other strategies for motivation were employed within some projects. Benton et al. (2014) highlighted the need for an adult to ensure that distracting resources were removed from view when working with children with dyslexia and Hornof (2009) discussed an effective way of building rapport with the teenagers with cerebral palsy he worked with through ornery activities which were deemed "borderline offensive" by their caregivers, but immensely enjoyed and engaging for the teenagers. Furthermore other researchers discussed the need for the adults running the design sessions to change or adapt design activities on the fly to help maintain engagement in those children who become bored or distracted (Malinverni et al., 2014; Mazzone et al., 2008).

\subsubsection{Caregiving}

Adults taking responsibility for the care and well-being of the children in response to non-task related issues was discussed in 13 of the projects. This often involved adults other than the researcher/designer as they were more likely to be familiar with the children and in a position to provide more appropriate care.

Within some projects the creation of a safe environment and the need to ensure the children felt at ease was explicitly discussed. This was achieved through the involvement of a familiar teacher (Benton et al., 2012; de Faria Borges et al., 2014) or parent (Piper et al., 2006; Ruland et al., 2008) who made sure the children felt at ease or the researcher/designer undertook the design session within a environment that felt safe to the child such as at their home (Hussain, 2010). Also by explicitly reassuring the children that there were "no right answers" in terms of the outcome of the design activities (Benton et al., 2014; Millen et al., 2010) and they did not need to worry about incorrect spellings or unwanted ideas being included within the game (Benton \& Johnson, 2013).

As often the researcher/designer was not familiar with the child participants many projects discussed the importance of building rapport/relationships with the children to help them feel more comfortable participating in the sessions. This could be achieved by frequent visits to the school (Piper et al., 2006), building a more informal relationship that is different to the teacher/student relationship through ground rules and including informal time to allow the children the opportunity to ask non-task related questions (Brederode et al., 2005; Foss et al., 2013; Gibson et al., 2002). Benton et al. (2012) also discuss the need for adults to build children's confidence through their personal strengths, which could be established through spending more informal time with them. Due to their particular difficulties children with SEND can often struggle more than other children and become upset/tired/stressed more easily during design sessions. Therefore some researchers discussed the need to be aware of this and adapt the session protocol accordingly (Brederode et al., 2005), initiate breaks where necessary (Millen et al., 2011; Piper et al., 2006), provide the opportunity to be removed from the design environment (Guha et al., 2008) and also recognize a child's "I'm done" signal to know when to finish the session (Hornof, 2009).

Lastly there can often be additional ethical guidelines defined by the institution where the design sessions are taking place (e.g. school, hospital, clinic) that need to be followed when working with particularly vulnerable groups such as children with SEND and it is important the all adults are aware of these and follow them accordingly (Durrant et al., 2013; Hornof, 2009).

\subsubsection{Contributing as Proxies}

Although not now prevalent, there has been a history in $\mathrm{HCl}$ of surrogates sometimes being used in place of users who are not generally available due to sparse numbers, dispersal, cost and so on. This has been almost universally viewed as not ideal and the resulting software evaluated and its utility understood within this context and circumstance. The assumption that designers or surrogates have similar human characteristics and abilities to end-users is not generally considered as an appropriate argument to mitigate the lack of end user involvement. On the one hand, it is also unlikely that adults acting as proxies for children with 
SEND can truly represent the children's views, perspectives, likes, dislikes, capabilities and abilities. On the other hand clearly those same characteristics, capabilities and abilities may mean that it is not possible or even advisable from the children's health and wellbeing perspective to try to engage the children in some or all of the design sessions. In this case suitable provisions have to be made to ensure adults fulfilling appropriate knowledge, expertise and experiential criteria are chosen as proxies either within some or all of the design sessions, or as interpreters of the meaning of any child contributions to those sessions. Within this review, any projects which solely included adults as proxies for children with SEND, where the children had no opportunity to directly impact the design decisionmaking process and the adults were totally responsible for interpreting the children's needs and preferences, have not been not included.

It is quite common for familiar adults such as parents, carers or teachers to participate on behalf of children with SEND during the technology design process due to the resulting challenges that a child's specific special educational need or disability can have during the technology design process. In some of the reviewed projects the involvement of the children was quite limited often due to communication difficulties and the adults who were familiar with the children, such as teachers/caregivers as well as experts, contributed to the design process on the children's behalf as proxies for the children at specific stages of the design process. This was particularly common early on, with teachers, parents, therapists, engineers, psychologists and psychiatrists (as well as in some cases children without SEND) being involved, alongside researchers/designers, in brainstorming sessions to define project goals as well as establish early design concepts (Culén et al., 2013; de Faria Borges et al., 2014; Keay-Bright, 2007b; López-Mencía et al., 2010; Malinverni et al., 2014; Ruland et al., 2008; Sampath et al., 2013). This enabled the later design sessions involving the children with SEND themselves to be more tightly focused.

There were some further actions that adults undertook when involving children with SEND in the technology design process, which have not been discussed as explicitly in the wider child PD literature. Due to the various communication difficulties some children with SEND can experience it was important within some projects that the adults helped to mediate/interpret the child's communication of ideas particularly between the children and researcher(s)/designer(s) who were unfamiliar with the child and their particular method of communication. This could sometimes involve the researcher/designer employing communication aids such as the use of technological tools (Frauenberger et al., 2013; Frauenberger, Good, Keay-Bright, et al., 2012; Hornof, 2009) or toys (van Rijn \& Stappers, 2008) or tailoring the communication to the child's ability level, for instance phrasing the questions to allow for one word answers (Allsop et al., 2009). Also the involvement of experts such as sign language interpreters to translate children's ideas (Henderson et al., 2005; Potter et al., 2011; Slegers et al., 2010) or adults familiar with the children, such as teachers, helpers and parents, to interpret their observations of children's reactions to prototypes (Holone \& Herstad, 2013; Keay-Bright, 2007a; Sampath et al., 2013; van Rijn \& Stappers, 2008) was reported.

In addition to this within several projects the adult's contributions were made during design sessions when the children were not present. This sometimes occurred through parallel design sessions involving practitioners, parents or carers to help reinforce or build on the children's ideas (Al-Wabil et al. 2010; Frauenberger et al. 2012) or involving caregivers and teachers in separate sessions to try out different versions of the prototype technology (Zarin \& Fallman, 2011). Adult only design sessions also often occurred between sessions with the children, where adult participants who participated in the design sessions with the children could use this experience along with their specific expertise to elaborate upon the current design concept. This involved researchers/designers along with members of the development team, language and education scientists and therapists (de Faria Borges et al., 2014) as well as teachers, parents, support staff and other experts (Keay-Bright 2007a, 2007b). Within other projects the majority of the adult's input into the design process occurred after the final design session involving the children. Frauenberger et al. (2012) describe in detail how the children's ideas informed and inspired the design of the ECHOES environment during a two day design session with the whole project team after all of the design sessions with the children had taken place in schools. Others followed a similar process building upon the 
children's contributions at later points in the process, using the adult's design expertise to turn ideas and inspiration into fully formed technology design concepts (Durrant et al., 2013; Hussain, 2010). Furthermore, adults, particularly those with the appropriate pedagogical knowledge such as teachers and education experts, made contributions to the design through ensuring proposed ideas met the pre-defined criteria in terms of pedagogical and educational content (Larsen \& Hedvall, 2012; Mazzone et al., 2008; Parsons \& Cobb, 2014; Ruland et al., 2008; Tarrin et al., 2006).

\subsubsection{Adults Contributing as Co-Designers}

The adult's design contributions between projects, partly depending on the role that the children were undertaking, also varied considerably in how these contributions were detailed within the literature.

In a subset of the projects the adults formed partnerships with the children and elaborated directly upon one another's ideas during joint design sessions. In some projects adults proposed ideas, which were shared with the children during the design sessions, providing examples to guide idea generation and inspiration and also that could be elaborated upon or changed by the children (Benton et al., 2014; Hornof, 2009; Malinverni et al., 2014). This could be a particularly effective approach for children who struggle with the initial idea generation process. Within other projects the adult researchers/designers worked alongside the children contributing ideas throughout the sessions as well as suggestions for how different participants' ideas could be integrated into a single concept and with idea elaboration occurring on both sides (Benton et al., 2012; Benton \& Johnson, 2013; Foss et al., 2013; Wärnestål et al., 2014). It should be noted that the children that participated within this idea elaboration all had sufficient cognitive and communication skills to be able to understand the adult's ideas and express their own ideas without extensive additional support.

Finally many of the projects failed to discuss anything about the adult's contributions to the design process other than that they implemented the children's ideas within the prototype technology (Holone \& Herstad 2013; Gibson et al. 2002; Allsop et al. 2009; Henderson et al. 2005; Iversen et al. 2007; Sánchez \& Flores 2004; McElligott \& van Leeuwen 2004; Grawemeyer et al. 2012; Rigby et al. 2006; Slegers et al. 2010; Hourcade et al. 2012; Brederode et al. 2005; Potter et al. 2011; Piper et al. 2006), making it difficult to establish the extent to which the different adult participants directly impacted the final outcome of the technology design process.

6.2 Discussion of adult roles, responsibilities and activities

The literature has shown that the involvement of children with SEND within the technology design process often results in a much wider cross-section of adult participants from a wide range of backgrounds also being involved. This bears similarities with the types of PD projects conducted with adults in the workplace, where everyone is seen as an expert in their own specific area and expected to contribute this expertise where it is seen as appropriate.

Many of the projects discussed in this paper highlight the importance of the involvement of adults other than the researchers/designers to the success of the design process, however if we are not clear about the roles, responsibilities and activities they are expected or allowed to undertake then it may be that valuable design contributions are being missed by the adults solely focusing on supporting the children's contributions. Ruland et al. (2008) highlight how crucial the knowledge of professional designers is to making the final design decisions before implementation, but that it is important these decisions are informed by "psychological and pedagogical insights" which is what the parents/caregivers, practitioners, specialists, teaching staff, therapists, health professionals and support workers involved in the design process can bring.

Within some of these projects adults are involved in various roles at different stages of the process. When adults are involved in workplace-based PD this can be quite common with various levels of management and workers able to play a more important role and contribute at different stages of the design process. This is made explicit in the work of Vink et al. (2008). In addition to being involved at different stages in the process it is possible that the roles and responsibilities of adult participants can overlap and evolve over time as they 
become more familiar with the other participants as well as the design process itself, becoming more involved and making different types of contributions as the project goes on. Although this would be more applicable to long term projects where participants are involved in multiple sessions, for instance Carroll et al. describe the changing role of the teachers they worked with during a PD project that spanned five years (Carroll et al., 2000).

\section{Recommendations for reporting future PD projects involving children with SEND}

Throughout this paper we have reviewed a number of reported studies of children with SEND being involved in the design of technology. The approaches, methodology and study designs (including adult and children's roles, responsibilities and activities, and their levels of participation) as well as outcomes and impacts, differ widely across the $\mathrm{CCl}$ literature. The broad range of articles included within this review suggests that this is a thriving, diverse and motivating research area attracting work of a high quality undertaken by engaged researchers. As a direct consequence of the research reported in the $\mathrm{CCl}$ literature there is a heightened awareness of the need to involve typically developing but also children with SEND in the design of technology for their own use, and the benefits this can bring. However, despite this growing body of work the majority of this research has focused on the involvement of a small minority within the SEND population. For instance a high proportion of the articles (19 out of 49) focused on children with autism, with seven articles focusing on children with physical impairments such as cerebral palsy and four articles focusing on children with hearing impairments. Children with special educational needs or disabilities outside of these were the focus of fewer than four articles with many groups of children still yet to participate in the technology design process in any way. We therefore encourage researchers to seek to involve children with a wider range of needs within the technology design process.

In moving forward within this research area we set out recommendations for future PD projects involving children with SEND based on the findings of this review. These recommendations are structured by the conceptual framework, a "tool-to-think-with", proposed by Frauenberger et al. (2015) which supports reflection upon the accountability (in terms of how the decision-making and outcomes were influenced by the PD process) and rigour (in terms of the justification for the approach followed) within PD work. This tool incorporates four lenses of critical reflection, which are discussed in relation to PD and children with SEND below.

\subsection{Epistemology}

Epistemology describes the construction of meaning or how we come to know what we know (Crotty, 1998). According to Frauenberger et al. (2015) there are four broad types of knowledge that may be constructed during the PD process, which include social, design, methodological and theoretical. These types of knowledge are grounded in specific epistemological positions within PD and it important for researchers to make these positions known.

A number of the reviewed articles offer insights into the methodological approach that was followed for a particular SEND population, with all but four articles at a minimum stating the specific design approach that was followed. These insights also sometimes resulted in new PD methods or approaches, for instance the IDEAS method developed by Benton et al. (2012) or the extension of the Cooperative Inquiry method by Foss et al. (2013). There was also some discussion within 18 of the articles around the design knowledge that was generated and how this indirectly (11 articles) or directly (seven articles) informed the technological artifact. However, the role of the designer in relation to this was rarely explicitly discussed, providing more detail about how the design knowledge is constructed, interpreted and used to inform the design outcomes needs would benefit other researchers aiming to follow similar processes or those looking to build on existing design knowledge. There are also opportunities for PD work in this area to contribute social knowledge about the life-worlds of children with a particular special need or disabilities to enable us to build on knowledge about the needs, preferences and experiences of these particular child populations. Furthermore there was little work that attempted to contribute substantially to theoretical 
knowledge in this area. This highlights a need for future research to focus on the design, social and theoretical knowledge generated from PD work alongside existing knowledge about the design methods and approaches.

The transferability of this generated knowledge is important to enable other researchers to build on previous work. However, due to the wide range of individual differences within and across SEND populations these forms of knowledge can be specific to certain contexts such as the severity or complexity of the child participant's special educational need or disability; the form and amount of adult support; the level and frequency of the child's involvement; the type of design environment etc. Therefore researchers need to describe in what ways the construction of knowledge is linked to a specific design context to enable it to be appropriately applied within other relevant PD project contexts.

\subsection{Stakeholders and Participants}

PD projects typically encompass a range of different stakeholders who may participate in the design process. This review highlighted that when children with SEND are participants then adults from a variety of different backgrounds and organisations are often involved. These adults can perform a variety of different roles, with their level of involvement and responsibilities often evolving over the design process in response to the types of design activity as well as particular children's needs. Seven articles detailed how the adults contributed directly in the design process and in other cases the adults' role was predominantly to support the children's participation through roles and responsibilities such as facilitation, motivation and caregiving. However, the nature of this participation in comparison to the child's was rarely discussed in any detail making it difficult to discern the extent to which different adults were involved and contributed towards the design process. Therefore researchers should seek to discuss the roles, responsibilities and level of involvement of the different adult participants as well as describe how the nature of their involvement evolved over the course of the design process.

Frauenberger et al. (2015) highlight the need to recognise the direct impact that involvement in PD can have on the participants themselves. This review has identified a range of beneficial impacts that involvement in PD can have on children with SEND, although it was found that these types of impact are typically not examined in a rigorous manner. Participation in the technology design process provides the opportunity for children with SEND to benefit in a range of ways from experiences that can be rare within their daily lives, for instance by developing new skills or abilities (six articles), encouraging positive behaviours (six articles), initiating positive emotions (11 articles) as well as generally providing a positive experience (18 articles). Therefore researchers in this area are urged to consider potential positive impacts in advance of children's participation in the technology design process as well as reflect if and how these have occurred at the end of the PD process.

\subsection{Values}

Frauenberger et al. (2015) state that the choice of PD approach is an expression of researcher values, and when involving children with SEND this can also be influenced by the model of disability to which they subscribe. The articles reviewed here generally did not state these researcher values explicitly, but many focused on either involving children with SEND in designing technology with the goal of assisting them with particular impairments associated with their special educational need or disability, e.g. communication aids, (nine articles) or to help them improve in a particular area of difficulty e.g. social skills or sign language (19 articles). Furthermore those articles which provided methodological details often focused on how PD methods were adapted to support or overcome associated impairments which were viewed as potential barriers to the involvement of a particular SEND population within the technology design process, although Benton et al. (2014) do explicitly discuss the social model of disability and its role within the neurodiverse movement. This guided the development of their PD framework for neurodiverse children within which they consider the strengths of these populations in relation to PD and in addition to their potential difficulties.

The review highlighted the range of backgrounds of the adult participants involved in the PD process with children with SEND, which include parents, teachers and medical professionals. The relationships these different adults have with the children may have a significant 
influence on the power structures within the design team, as typically these adults make many decisions on their behalf, more so than for typically developing children. It is important to recognise that the different values of the adult participants are embedded within the design decisions made during the PD process and that values particularly around the nature of disability within society can influence the potential for the empowerment of children with SEND within the decision-making process. Researchers need to be explicit about this process, and also where adults are used as proxies for children, provide the justification for this decision. Therefore researchers should be mindful of the values held by different groups of participants as well as their own personal values, particularly with regards to disability. They should provide justification for why certain groups of participants were involved, and reflect upon how the design decisions may have been impacted by these different values as well as describe how and in what ways (i.e. directly or indirectly) children with SEND have impacted the resulting technology.

\subsection{Outcomes}

Frauenberger et al. (2015) note that it is nearly impossible to judge the impact of participation on the outcomes of the process, i.e. what was different from following a non-participatory approach to design. However, it is important to recognise a range of different outcomes beyond simply the technology and that different stakeholders may interpret the outcomes of the design process in different ways. These outcomes could also include changes to local practices or social change as well as improving the knowledge, skills and/or abilities of individual participants. The articles within this review have predominantly focused on describing the technological outcome, which is frequently little more than a prototype design that would not be sustainable beyond the end of the project. However, there are opportunities for children with SEND to be listened to and to demonstrate their knowledge, skills and/or abilities that may not have previously been recognized, as well as for potential changes to the balance of power within relationships between the children and adults. The PD process also offers opportunities for mutual learning and in this particular context for adult participants to learn more about the strengths and abilities of specific SEND populations through the design process. These are all outcomes that could potentially be more sustainable beyond the end of a PD project as well as bring about positive changes for the participants. Therefore it is important that researchers recognise and discuss a range of different outcomes for different participants beyond simply the technological contributions of the design process.

\section{Conclusion}

This review has shown that within $\mathrm{CCl}$, the sub-field that is involving SEND populations in the technology design process is growing rapidly and the papers we have discussed here show the wide and exciting range of existing research projects taking place within this community. We have been encouraged by the work that has taken place to date, but there is also much more to do and we appeal for more work to be undertaken in this important area of research. We hope this paper will aid $\mathrm{CCI}$ researchers in this challenge by allowing them to situate their work within the current research landscape and to enable them to more easily build on the multitude of methods and techniques that have already been developed and used in previous work with children with SEND. This in turn should help to increase the opportunities for many more children to actively participate in a process that is both meaningful and beneficial to their lives.

\section{Acknowledgements}

The authors would like to thank the IJCCI reviewers as well as Asimina Vasalou for their valuable comments and feedback on this paper. The first author was funded by the Mike Ashworth PhD Scholarship and the EU FP7 ICT project iLearnRW (project number: 318803), which made this work possible.

\section{References}

Al-Wabil, A., Meldah, E., Al-Suwaidan, A., \& AlZahrani, A. (2010). Designing Educational Games for Children with Specific Learning Difficulties: Insights from Involving Children 
and Practioners. In Fifth International Multi-conference on Computing in the Global Information Technology (pp. 195-198). IEEE.

Allsop, M., Holt, R., Levesley, M., \& Bhakta, B. (2009). Involving children in the design of healthcare equipment: an investigation into methodology. In Proceedings of INCLUDE 2009.

Anderberg, P. (2005). Making both ends meet. Disability Studies Quarterly, 25(3).

Armagno, G. (2012). The Role of $\mathrm{HCl}$ in the Construction of Disability. In Proceedings of $\mathrm{HCl}$ Ethics 2012. British Informatics Society Ltd.

Benton, L. (2013). Participatory Design and Autism: Supporting the participation, contribution and collaboration of children with ASD during the technology design process. Doctoral Thesis. University of Bath.

Benton, L., \& Johnson, H. (2013). Structured approaches to participatory design for children: can targeting the needs of children with autism provide benefits for a broader child population? Instructional Science, 42(1), 47-65. doi:10.1007/s11251-013-9297-y

Benton, L., Johnson, H., Ashwin, E., Brosnan, M., \& Grawemeyer, B. (2012). Developing IDEAS: Supporting children with autism within a participatory design team. In Proceedings of the 2012 annual conference on Human factors in computing systems (pp. 2599-2608). Austin, Texas, USA: ACM Press.

Benton, L., Vasalou, A., Khaled, R., Johnson, H., \& Gooch, D. (2014). Diversity for Design: A Framework for Involving Neurodiverse Children in the Technology Design Process. In Proceedings of the SIGCHI conference on Human Factors in Computing Systems (pp. 3747-3756). ACM.

Bossen, C., Dindler, C., \& Iversen, O. S. (2010). User gains and PD aims: assessment from a participatory design project. Proceedings of the 11th Biennial Participatory Design Conference. Sydney, Australia: ACM Press.

Bossen, C., Dindler, C., \& Iversen, O. S. (2012). Impediments to user gains: experiences from a critical participatory design project. Proceedings of the 12th Participatory Design Conference. Roskilde, Denmark: ACM Press.

Brederode, B., Markopoulos, P., Gielen, M., Vermeeren, A., \& der Ridden, H. (2005). pOwerball: The design of a novel mixed-reality game for children with mixed abilities. Proceedings of the 4th International Conference for Interaction Design and Children. Boulder, USA: ACM Press.

Carroll, J. M., Chin, G., Rosson, M. B., \& Neale, D. C. (2000). The development of cooperation: five years of participatory design in the virtual school. In Proceedings of the 3rd conference on Designing interactive systems: processes, practices, methods, and techniques (pp. 239-251). ACM.

Crotty, M. (1998). The foundations of social research: Meaning and perspective in the research process. London: Sage Publications.

Culén, A., van der Velden, M., \& Karpova, A. (2013). Challenges in Designing Learning Apps for and with Vulnerable Children. In Proceedings of CHI 2013 Workshop on Designing for and with Vulnerable People.

De Faria Borges, L. C. L., Filgueiras, L. V. L., Maciel, C., \& Pereira, V. C. (2014). The life cycle of a customized communication device for a child with cerebral palsy: 
contributions toward the PD4CAT method. Journal of the Brazilian Computer Society, 20(1), 1-23.

Dearden, A., \& Rizvi, H. (2008). Participatory IT design and participatory development: a comparative review. In Proceedings of the tenth anniversary conference on Participatory Design (pp. 81-91). ACM.

Druin, A. (2002). The role of children in the design of new technology. Behaviour and IT, 21(1), 1-25.

Durrant, A., Hook, J., Mcnaney, R., Williams, K., Smith, T., Kipling, M., ... Olivier, P. (2013). Design to support interpersonal communication in the special educational needs classroom. In Proceedings of the 12th International Conference on Interaction Design and Children - IDC '13 (pp. 46-55). ACM.

Dept. for Education \& Dept. for Health (2014). Special educational needs and disability code of practice: 0 to 25 years. Retrieved from https://www.gov.uk/government/uploads/system/uploads/attachment_data/file/342440/S END_Code_of_Practice_approved_by_Parliament_29.07.14.pdf

Foss, E., Guha, M. L., Papadatos, P., Clegg, T., Yip, J., \& Walsh, G. (2013). Cooperative Inquiry Extended: Creating Technology with Middle School Students with Learning Differences. Journal of Special Education Technology, 28(3).

Franklin, A., \& Sloper, P. (2009). Supporting the Participation of Disabled and Young People in Decision-making. Children \& Society, 23(1), 3-15.

Frauenberger, C., Good, J., \& Alcorn, A. (2012). Challenges, Opportunities and Future Perspectives in Including Children with Disabilities in the Design of Interactive Technology. In Proceedings of 11th International Conference on Interaction Design and Children (pp. 367-370). Bremen, Germany: ACM.

Frauenberger, C., Good, J., Alcorn, A., \& Pain, H. (2012). Supporting the Design Contributions of Children with Autism Spectrum Conditions. In Proceedings of the 11th International Conference on Interaction Design and Children (pp. 134-143). Bremen, Germany: ACM Press.

Frauenberger, C., Good, J., Alcorn, A., \& Pain, H. (2013). Conversing through and about technologies: Design critique as an opportunity to engage children with autism and broaden research(er) perspectives. International Journal of Child-Computer Interaction, In Press.

Frauenberger, C., Good, J. Fitzpatrick, G. \& Iversen, O.S. (2015). In pursuit of rigour and accountability in participatory design. International Journal of Human-Computer Studies, 74, 93-106.

Frauenberger, C., Good, J., \& Keay-Bright, W. (2010). Phenomenology, a Framework for Participatory Design. In Proceedings of the 11th Biennial Participatory Design Conference (pp. 187-190). ACM.

Frauenberger, C., Good, J., \& Keay-Bright, W. (2011). Designing Technology for Children with Special Needs - Bridging Perspectives through Participatory Design. CoDesign: International Journal of CoCreation in Design and the Arts, 7(1), 1-28.

Frauenberger, C., Good, J., Keay-Bright, W., \& Pain, H. (2012). Interpreting input from children: a designerly approach. In Proceedings of the SIGCHI conference on Human Factors in Computing Systems - CHI '12 (pp. 2377-2386). ACM. 
Gibson, L., Gregor, P., \& Milne, S. (2002). Case study: Designing with difficult children. Proceedings of the 1st International Conference for Interaction Design and Children. Eindhoven, The Netherlands: Shaker Publishing.

Good, J., \& Robertson, J. (2006). CARSS: A Framework for Learner-Centred Design with Children. International Journal of Artificial Intelligence in Education, 16(4), 381-413. Retrieved from http://dl.acm.org/citation.cfm?id=1435358.1435362

Grawemeyer, B., Johnson, H., Brosnan, M., Ashwin, E., \& Benton, L. (2012). Developing an Embodied Pedagogical Agent With and For Young People with Autism Spectrum Disorder. In Proceedings of the 11th international conference on Intelligent Tutoring Systems (pp. 262-267). Chania, Crete, Greece: Springer-Verlag.

Guha, M. L., Druin, A., Chipman, G., Fails, J. A., Simms, S., \& Farber, A. (2004). Mixing ideas: a new technique for working with young children as design partners. In Proceeding of the 2004 conference on Interaction design and children building a community - IDC '04 (pp. 35-42). New York, New York, USA: ACM.

Guha, M. L., Druin, A., \& Fails, J. (2008). Designing with and for children with special needs: An inclusionary model. In Proceedings of the 7th International Conference for Interaction Design and Children (pp. 61-64). Chicago, USA: ACM Press.

Guha, M. L., Druin, A., \& Fails, J. A. (2010). Investigating the impact of design processes on children. In Proceedings of the 9th International Conference on Interaction Design and Children (pp. 198-201). Barcelona, Spain.

Guha, M. L., Druin, A., \& Fails, J. A. (2013). Cooperative Inquiry revisited: Reflections of the past and guidelines for the future of intergenerational co-design. International Journal of Child-Computer Interaction, 1(1), 14-23.

Hart, R. A. (1992). Children's participation: from tokenism to citizenship. Florence: Unicef.

Henderson, V., Lee, S., Brashear, H., Hamilton, H., Starner, T., \& Hamilton, S. (2005). Development of an American Sign Language game for deaf children. In Proceedings of the 2005 conference on Interaction design and children (pp. 70-79). ACM.

Hernandez, H. A., Ye, Z., Graham, T. C. N., Fehlings, D., \& Switzer, L. (2013). Designing Action-based Exergames for Children with Cerebral Palsy. In Proceedings of the SIGCHI Conference on Human Factors in Computing Systems (pp. 1261-1270). ACM.

Holone, H., \& Herstad, J. (2013). Three tensions in participatory design for inclusion. In Proceedings of the SIGCHI conference on Human factors in Computing Systems - CHI '13 (pp. 2903-2906). ACM.

Hornof, A. J. (2009). Design with Children with Severe Motor Impairments. Proceedings of the SIGCHI Conference on Human Factors in Computing Systems. Boston, USA: ACM Press.

Hourcade, J. P., Bullock-Rest, N. E., \& Hansen, T. E. (2012). Multitouch Tablet Applications and Activities to Enhance the Social Skills of Children with Autism Spectrum Disorders. Personal and Ubiquitous Computing, 16(2), 157-168.

Hussain, S. (2010). Empowering marginalised children in developing countries through participatory design processes. CoDesign: International Journal of CoCreation in Design and the Arts, 6(2), 99-117. 
Iversen, O. S., Kortbek, K. J., Nielson, K. R., \& Aagaard, L. (2007). Stepstone: an interactive floor application for hearing impaired children with a cochlear implant. In Proceedings of the 6th international conference on Interaction design and children (pp. 117-124). ACM.

Keay-Bright, W. (2007a). Can computers create relaxation? Designing ReacTickles software with children on the autistic spectrum. CoDesign: International Journal of CoCreation in Design and the Arts, 3(2), 97-110.

Keay-Bright, W. (2007b). The Reactive Colours Project: Demonstrating Participatory and Collaborative Design Methods for the Creation of Software for Autistic Children. Design Principles and Practices: An International Journal, 1(2), 7-16.

Larsen, H. S., \& Hedvall, P.-O. (2012). Ideation and ability: when actions speak louder than words. In Proceedings of the 12th Participatory Design Conference (pp. 37-40). ACM.

López-Mencía, B., Pardo, D., Hernández-Trapote, A., Hernández, L., \& Relaño, J. (2010). A collaborative approach to the design and evaluation of an interactive learning tool for children with special educational needs. In Proceedings of the 9th International Conference on Interaction Design and Children (pp. 226-229). ACM.

Madsen, M., el Kaliouby, R., Eckhardt, M., Hoque, M. E., Goodwin, M. S., \& Picard, R. (2009). Lessons from participatory design with adolescents on the autism spectrum. Proceedings of the SIGCHI Conference on Human Factors in Computing Systems. Boston, USA: ACM Press.

Malinverni, L., MoraGuiard, J., Padillo, V., Mairena, M. A., Hervás, A., \& Pares, N. (2014). Participatory design strategies to enhance the creative contribution of children with special needs. In Proceedings of the 2014 conference on Interaction design and children (pp. 85-94). ACM.

Mankoff, J., Hayes, G. R., \& Kasnitz, D. (2010). Disability Studies as a Source of Critical Inquiry for the Field of Assistive Technology. In Proceedings of the 12th international ACM SIGACCESS conference on Computers and accessibility (pp. 3-10). ACM.

Mazzone, E., livari, N., Tikkanen, R., Read, J. C., \& Beale, R. (2010). Considering Context, Content, Management, and Engagement in Design Activities with Children. Proceedings of the 9th International Conference on Interaction Design and Children. Barcelona, Spain: ACM Press.

Mazzone, E., Read, J. C., \& Beale, R. (2008). Design with and for disaffected teenagers. In Proceedings of the 5th Nordic conference on Human-computer interaction: building bridges (pp. 290-297). Lund, Sweden: ACM.

McElligott, J., \& van Leeuwen, L. (2004). Designing sound tools and toys for blind and visually impaired children. In Proceedings of the 3rd International conference for Interaction Design and Children (pp. 65-72). Maryland, USA: ACM Press.

Millen, L., Cobb, S., \& Patel, H. (2010). Participatory design with children with autism. In Proc. Disability, Virtual Reality and Associated Technologies (pp. 93-102). Viña del Mar/Valparaíso, Chile.

Millen, L., Cobb, S., \& Patel, H. (2011). A method for involving children with autism in design. In Proceedings of the 10th International Conference on Interaction Design and Children (pp. 185-188). Ann Arbor, USA: ACM. 
Nesset, V., \& Large, A. (2004). Children in the information technology design process: A review of theories and their applications. Library \& Information Science Research, 26(2), $140-161$.

Parsons, S., \& Cobb, S. (2014). Reflections on the role of the "users": challenges in a multidisciplinary context of learner-centred design for children on the autism spectrum. International Journal of Research \& Method in Education, 1-21.

Piper, A. M., O'Brien, E., Morris, M. R., \& Winograd, T. (2006). SIDES: a cooperative tabletop computer game for social skills development. Proceedings of the 2006 20th Anniversary Conference on Computer Supported Cooperative Work. Banff, Canada: ACM Press.

Potter, L. E., Korte, J., \& Nielsen, S. (2011). Seek and Sign: an early experience of the joys and challenges of software design with young deaf children. In Proceedings of the 23rd Australian Computer-Human Interaction (pp. 257-260). ACM].

Read, J. C., Fitton, D., \& Horton, M. (2014). Giving ideas an equal chance: inclusion and representation in participatory design with children. In Proceedings of the 2014 conference on Interaction design and children (pp. 105-114). ACM.

Read, J. C., Gregory, P., MacFarlane, S., McManus, B., Gray, P., \& Patel, R. (2002). An Investigation of Participatory Design with Children - Informant, Balanced and Facilitated Design. Proceedings of Interaction Design and Children. Eindhoven, Netherlands: Shaker Publishing.

Rigby, P., Ryan, S., From, W., Walczak, E., \& Jutai, J. (2006). A client-centred approach to developing assistive technology with children. Occupational Therapy International, 3(1), 67-79.

Rogers, Y., Sharp, H., \& Preece, J. (2011). Interaction Design: beyond human-computer interaction (3rd ed.). Chicester: Wiley.

Ruland, C. M., Starren, J., \& Vatne, T. M. (2008). Participatory design with children in the development of a support system for patient-centred care in pediatric oncology. Journal of Biomedical Informatics, 41(4), 624-635.

Sampath, H., Agarwal, R., \& Indurkhya, B. (2013). Assistive Technology for Children with Autism - Lessons for Interaction Design. In Proceedings of the 11th Asia Pacific Conference on Computer Human Interaction (pp. 325-333). ACM.

Sánchez, J., \& Flores, H. (2004). Memory enhancement through audio. In Proceedings of the 6th international ACM SIGACCESS conference on Computers and accessibility (pp. 2431). ACM.

Sanders, E. B.-N., \& Stappers, P. J. (2008). Co-creation and the new landscapes of design. CoDesign, 4(1), 5-18.

Scaife, M., \& Rogers, Y. (1999). Kids as informants: Telling us what we didn't know or confirming what we knew already. In A. Druin (Ed.), The design of children's technology (pp. 27-50). San Francisco: Kaufmann.

Scaife, M., Rogers, Y., Aldrich, F., \& Davies, M. (1997). Designing for or designing with? Informant design for interactive learning environments. Proceedings of the SIGCHI Conference on Human Factors in Computing Systems - CHI '97, 343-350. doi:10.1145/258549.258789 
Schuler, D., \& Namioka, A. (1993). Participatory Design: Principles and Practices. Mahwah, NJ: Lawrence Erlbaum Associates Inc.

Seelman, K. (2004). Trends in rehabilitation and disability: Transition from a medical model to an integrative model. Disability World, 22.

Slegers, K., Duysburgh, P., \& Jacobs, A. (2010). Research methods for involving hearing impaired children in IT innovation. In Proceedings of the 6th Nordic Conference on Human-Computer Interaction: Extending Boundaries - NordiCHI '10 (pp. 781-784).

Tarrin, N., Petit, G., \& Chêne, D. (2006). Network force-feedback applications for hospitalized children in sterile room. In Proceedings of the International Conference on Interaction Design and Children (pp. 157-160). ACM.

UNICEF. (2008). Convention on the Rights of the Child. Retrieved from http://www.unicef.org/crc/

Van Rijn, H. (2012). Meaningful encounters: Explorative studies about designers learning from children with autism. TU Delft.

Van Rijn, H., \& Stappers, P. J. (2008). Expressions of ownership motivating users in a codesign process. In Proceedings of the tenth anniversary conference on participatory design (pp. 178-181). Indianapolis, IN, USA: ACM.

Vines, J., Clarke, R., Wright, P., Iversen, O. S., Leong, T. W., McCarthy, J., \& Olivier, P. (2012). Summary Report on CHI 2012 invited SIG: Participation and HCl: Why Involve People in Design?. Retrieved from http://di.ncl.ac.uk/participation/chi2012/

Vink, P., Imada, A. S., \& Zink, K. J. (2008). defining stakeholder involvement in participatory design processes. Applied Ergonomics, 39(4), 519-526.

Wärnestål, P., Svedberg, P., \& Nygren, J. (2014). Co-constructing child personas for healthpromoting services with vulnerable children. In Proceedings of the SIGCHI conference on Human factors in computing systems - CHI '14 (pp. 3767-3776). ACM.

Zarin, R., \& Fallman, D. (2011). Through the Troll Forest : Exploring Tabletop Interaction Design for Children with Special Cognitive Needs. In Proceedings of the SIGCHI Conference on Human Factors in Computing Systems (pp. 3319-3322). ACM. 